\title{
Heavy Rainfall Events in Southern China Associated with Tropical Cyclones in the Bay of Bengal: A Case Study
}

\author{
Junpeng Yuan ${ }^{1, *}$, Jiao Lü ${ }^{1,2}$, Dian Feng ${ }^{1}$, Mengni Mao ${ }^{1}$, Tao Feng ${ }^{1}$, Juyue Yin ${ }^{1}$ and Ling Zuo ${ }^{1}$ \\ 1 Key Laboratory of Atmospheric Environment and Processes in the Boundary Layer over the Low-latitude \\ Plateau Region, Department of Atmospheric Sciences, Yunnan University, Kunming 650091, China; \\ LVJIAO6571@163.com (J.L.); fengdian94@163.com (D.F.); mao253546@sina.cn (M.M.); \\ taofeng@ynu.edu.cn (T.F.); yjuyue@163.com (J.Y.); EddyZoo@mail.ynu.edu.cn (L.Z.) \\ 2 China Eastern Yunnan Airlines, Kunming 650000, China \\ * Correspondence: jpyuan@ynu.edu.cn
}

Received: 19 August 2019; Accepted: 21 September 2019; Published: 23 September 2019

\begin{abstract}
We use a case study to show that a continuous heavy rainfall process in southern China was closely related to tropical cyclone activity in the Bay of Bengal. The continuous heavy rainfall that occurred in southern China on 11-13 May 2002 can be considered as two different processes. The first process, referred to as a predecessor rain event, occurred over southwestern China before landfall of the tropical cyclone. The second process occurred after dissipation of the tropical cyclone when its remnant caused heavy rainfall that expanded from southwestern China to the middle to lower reaches of the Yangtze-Huaihe river basin. Both of the heavy rainfall processes were closely related to the transport of warm, moist air associated with a tropical cyclone originating over the Bay of Bengal, but the mechanisms in the two processes were quite different. Low-level orographic forcing was the main contributor to the predecessor rain event, whereas baroclinic frontogenesis induced by thermal advection was the main contributor to the tropical cyclone remnant event. Both heavy rainfall events occurred beneath the equatorial entrance of the upper level East Asian subtropical jet.
\end{abstract}

Keywords: Bay of Bengal; tropical cyclone; southern China; heavy rainfall event; predecessor rain event; tropical cyclone remnant

\section{Introduction}

Tropical cyclones (TCs) are the most destructive weather systems. TCs can lead to heavy rainfall when approaching or making landfall. Besides the well-known rain shields surrounding the TC vortex, TCs also can convey abundant water vapor forward and produce heavy rainfall at a large distance from the TC vortex [1,2]. Cote suggested this type of remote TC rainfall be termed a "predecessor rain event (PRE)" to describe the organized heavy rainfall that occurs far ahead of a TC but is closely connected to it [3]. Occasionally, even after landfall and dissipation, the TC remnant also can remain active and cause heavy rainfall, especially when encountering other mid-latitude systems $[4,5]$.

Numerous studies have focused on the heavy rainfall events related to the TCs in the North Pacific and Atlantic Oceans. However, there is less research in North Indian Ocean. Moreover, owing to the narrow sea basin size and complex surrounding topography of the North Indian Ocean, the rainfall events caused by TCs in the North Indian Ocean are more complicated [6,7]. For example, TCs originating from the Bay of Bengal (BOB) not only can make landfall and affect surrounding countries directly [6], they can also have indirect effects and cause heavy rainfall and secondary landslides and debris flows in regions remote from the BOB, such as southwestern China [8-11]. Owing to the blocking effect of mountains, such as the Himalaya, the Naga Mountains and the Hengduan 
Mountains in China (Figure 1), the BOB TCs often weaken rapidly and cannot affect China directly. However, satellite cloud images indicate that zonal cloudy belts can extend from the TC vicinity in BOB to southwestern China [8]. The BOB TCs may provide plentiful moist air to southwestern China and cause remote heavy rainfall therein. In addition, the remnants of BOB TC can remain active for a few days after TC dissipation and, in consequence, generate heavy rainfall in southwestern China [7]. Occasionally, the influence of BOB TCs can also spread downstream to the east from southwestern China to the middle to lower reaches of the Yangtze-Huaihe river basin [10].

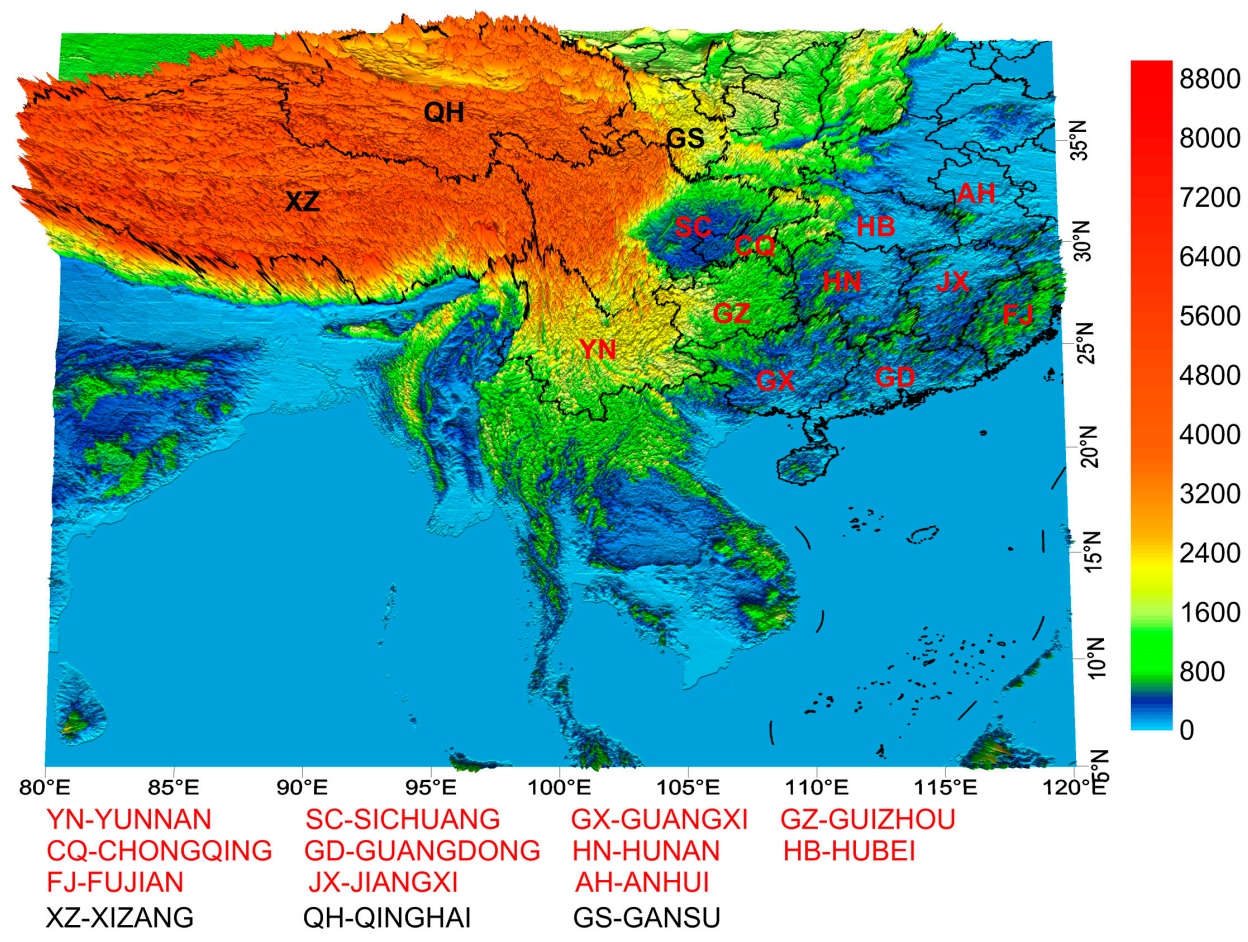

Figure 1. Digital elevation model of the topography around the Bay of Bengal and southern China. The locations of the provinces in southern China are labeled with acronyms.

However, how the BOB TCs produce remote "indirect" influences in southern China remains unclear. Recently, Yuan et al. reported that even before TC makes landfall, abundant moisture near the TC in BOB is advected to southwestern China, resulting in heavy rainfall [11]. This performs like a PRE that was suggested by Cote [3]. Based on the work of Cote [3], Yuan et al. further redefined PRE over southwestern China associated with BOB TC by satisfying the following criteria: (1) A coherent heavy rainfall region in southwestern China is clearly separate from the area of rainfall that is directly tied to BOB TC vortex, (2) deep tropical moisture originally associated with the BOB TC must be advected away from TC vicinity into the coherent rainfall region in southwestern China [11]. By identifying 21 PREs associated with BOB TCs during 1981-2012, Yuan et al. revealed that the PREs mainly occurred on the southwest side of the mountains in southwestern China. The topographic forced upward motion is very important for the PREs over southwestern China. Because the southwesterly wind conveys plentiful warm and moist air from the BOB TC vicinity and hits the mountains on the southwest side, it triggers strong ascent and is favorable for heavy rainfall occurrence therein [11]. Moreover, owing to high mountains southeast of Qinghai-Tibet Plateau, the mid-latitude systems and cold flows are hard to affect the southwest side of the mountains in southwestern China. The PREs that occur over southwestern China are mainly produced by the interactions of the TC and subtropical weather systems, such as the western Pacific subtropical high, the India-Burma trough and subtropical jet [1,8-12]. Hence, this is quite different from PREs caused by TCs in North Pacific and Atlantic Oceans. In that scenario, PREs usually occurred when abundant warm and moist air mass advected 
poleward from the TC vicinity to a quasi-stationary baroclinic zone in the mid-latitude, which are mainly produced by the interactions of the TC and mid-latitude systems $[3,13,14]$.

However, it should be noted that the remote heavy rainfall events associated with BOB TCs not only occur in southwestern China. Occasionally, the influences can also expand further eastward downstream to the middle to lower reaches of the Yangtze-Huaihe river basin. In this scenario, continuous heavy rainfall may start before the BOB TC's landfall and be sustained for several days even after the TC's dissipation. For example, a TC generated in the southeastern BOB on 9 May 2002, then moved northeast and made landfall on the western coast of Indo-China Peninsula at 00:00 on 12 May. Finally, the TC was dissipated at 12:00 on 12 May. Accompanying with the TC appearing in BOB, continuous heavy rainfall occurred on 11-13 May over remote southern China. A heavy rainfall belt expands from southwestern China to the middle to lower reaches of the Yangtze-Huaihe river basin (including Xizang, Yunnan, Guizhou, Sichuan, Chongqing, Guangxi, Hunan and Jiangxi provinces in southern China) (Figure 2). The previous study reported that the continuous heavy rainfall event was closely related to the abundant water vapor originated from the TC in BOB [15]. While this case cannot be treated just as a simple PRE. First, the continuous heavy rainfall event lasts over three days which were started from one day before the BOB TC's landfall to two days after TC's dissipation. Second, the heavy rainfall in southern China took place even over $2000 \mathrm{~km}$ away from the BOB TC. These characteristics are quite different from the typical PREs described by Yuan et al., which last about one or two days and take place up to $1000 \mathrm{~km}$ away from the BOB TC [11]. Thus, the continuous heavy rainfall that occurred on 11-13 May may have consisted of multiple processes, such as the PRE and TC remnant event. In addition, both of the processes and mechanisms between the PREs and TC remnant rainfall events may perform very differently. However, the detailed processes and their differences are not distinguished and clearly understood. Thus, in this work, we study the above-mentioned case and determine whether: (1) Multiple processes contributed to the heavy rainfall event that occurred over southern China on 11-13 May 2002 and whether and how the processes are associated with the remote BOB TC (2) If the continuous heavy rainfall event includes multiple processes, what are the differences between each process and related mechanisms?

(a)

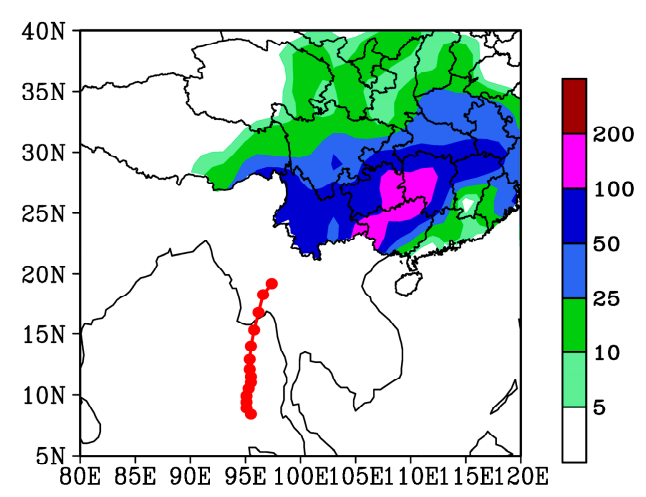

(b)

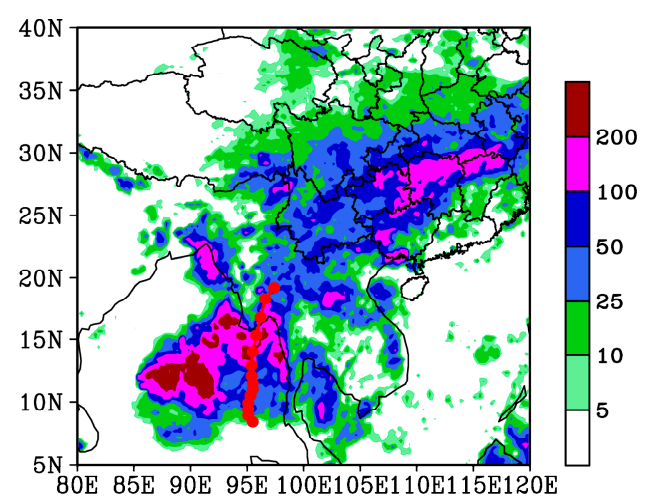

Figure 2. 72-h accumulated precipitation (units: $\mathrm{mm}$ ) from 11 to 13 May 2002 obtained from (a) the China Meteorological Administration and (b) the Tropical Rainfall Measuring Mission. The red lines indicate TC trajectories.

The paper is organized as follows. The datasets and methods are introduced in Section 2. The detailed characteristics of heavy rainfall associated with the BOB TC are described in Section 3.1. Section 3.2 shows the air parcel transport trajectories associated with the heavy rainfall event. The circulation environments and possible factors affecting the occurrence of heavy rainfall are shown in Sections 3.3 and 3.4, respectively. Our summary and discussion are presented in Section 4. 


\section{Data and Methods}

\subsection{Datasets}

We used the Joint Typhoon Warning Centre best-track dataset for TCs over the BOB, which includes the locations and intensities of TC at 6-h intervals [16]. We also used the European Center for Medium-Range Weather Forecasts Interim Reanalysis 6-h atmospheric datasets with a horizontal resolution of $0.5^{\circ} \times 0.5^{\circ}$ and a vertical resolution of 32 levels [17] and the Japan Meteorological Agency 1-h black body temperature (TBB) dataset on a $0.05^{\circ} \times 0.05^{\circ}$ grid. The TBB data was utilized to show the cloudiness variation. Note that lower TBB reflects more vigorous cloud development. We obtained the daily precipitation data observed at 834 stations over China from the China Meteorological Administration (CMA). We used the satellite-based 3-h precipitation analyses from the Tropical Rainfall Measuring Mission satellite (TRMM) 3B42 version 6 with a horizontal resolution of $0.25^{\circ} \times 0.25^{\circ}$ to analyze the detailed precipitation processes associated with TC [18,19]. We used reanalysis datasets obtained from the National Centers for Environmental Prediction/National Center for Atmospheric Research (NCEP/NCAR) with a horizontal resolution of $2.5^{\circ} \times 2.5^{\circ}$ and a vertical resolution of 17 levels to run the Hybrid Single-Particle Lagrangian Integrated Trajectory (HYSPLIT) model [20-22].

\subsection{Methods}

We computed the two-dimensional horizontal frontogenesis function, developed by Ninomiya, based on the ERA-Interim dataset to investigate the role of frontogenesis in heavy rainfall processes [23]. The evaluation for frontogenesis is computed as the rate of change in the magnitude of the horizontal equivalent potential temperature $\left(\theta_{\mathrm{se}}\right)$ gradient. We used the HYSPLIT model to verify the air parcel transport trajectories associated with the heavy rainfall event. A detailed description of the HYSPLIT model has been reported previously [24]. We calculated the forward (backward) air parcel trajectories in the vicinity of TCs (heavy rainfall regions) in the BOB (southern China) using the HYSPLIT model and the NCEP/NCAR reanalysis dataset. Note that we show the date in UTC time in this work.

\section{Results}

\subsection{Characteristics of Heavy Rainfall Events Associated with TCs in the BOB}

As a TC formed in BOB and moved northward to the west coast of the Indo-China peninsula on 9-12 May 2002, continuous heavy rainfall occurred on 11-13 May over southern China (Figure 2). The observational rainfall data obtained from CMA shows that a heavy rainfall belt expands from southwestern China to the middle to lower reaches of the Yangtze-Huaihe river basin. There were eight provinces in southern China that recorded heavy rainfall exceeding $50 \mathrm{~mm}$ in $72 \mathrm{~h}$, including Xizang, Yunnan, Guizhou, Sichuan, Chongqing, Guangxi, Hunan, and Jiangxi provinces (Figure 2a). The satellite-based TRMM precipitation analysis also shows that, besides the heavy rain shields surrounding the TC vortex in BOB, a zonal heavy rainfall belt appeared in southern China. Moreover, a distinct heavy rainfall region with exceeding $100 \mathrm{~mm}$ in $72 \mathrm{~h}$ presented in the middle to lower reaches of the Yangtze-Huaihe river basin, where was at a large distance from the BOB TC vortex (Figure 2b). Compared with the CMA rainfall data, the high-resolution TRMM precipitation analysis shows a similar heavy rainfall belt in southern China, but with more detailed configures (Figure 2b). Thus, in the following text, we use the TRMM data to reveal the detailed rainfall processes on 11-13 May.

A tropical depression formed in the southeastern BOB at 06:00 on 9 May 2002. The center of the depression had a maximum wind speed of 25 knots and a minimum pressure of $1002 \mathrm{hPa}$ at sea-level. Then, the TC moved to the northeast and gradually increased in intensity to a tropical storm by 12:00 on 10 May. As the TC moved northward to the northern Andaman Sea on 11 May, heavy rainfall began at 00:00 in southwestern China, including the provinces of Tibet, Yunnan and Sichuan (Figure 3a). Simultaneously, the satellite cloud images suggested that a cloudy region with low TBB appeared over the southeastern Qinghai-Tibetan Plateau, far ahead of the TC (Figure 4a). As the TC approached land 
at 21:00 on May 11, the convective clouds still sustained development and heavy rainfall occurred over the southeast of the Qinghai-Tibetan Plateau (Figures $3 b$ and $4 b$ ). The TC made landfall in southern Myanmar at 00:00 on 12 May and a region of strong convection with a minimum TBB less than $-60^{\circ} \mathrm{C}$ appeared over southwestern China (Figure 4c), which experienced extremely heavy rainfall with a maximum rainfall rate $>15 \mathrm{~mm} \mathrm{~h}^{-1}$ (Figure 3c).

(a)

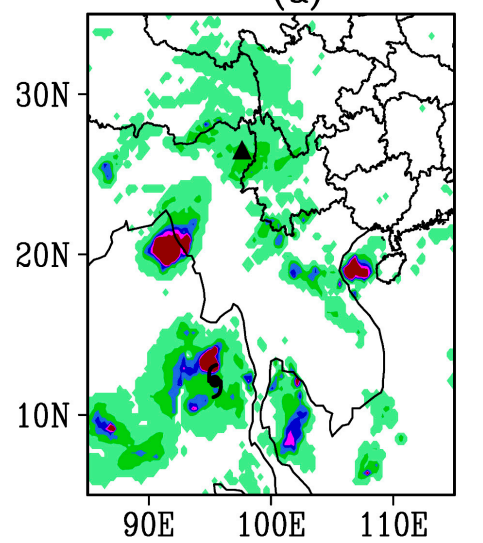

(c)

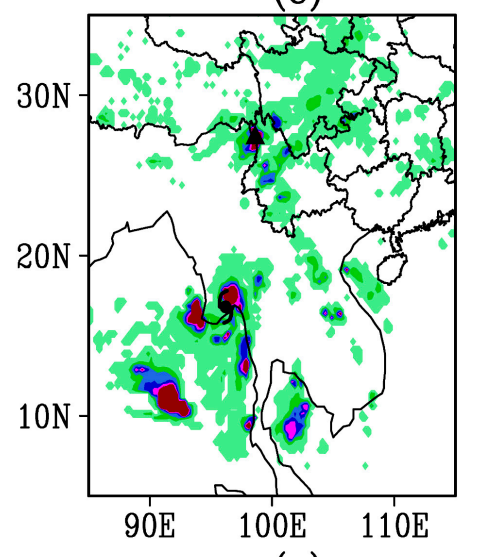

(e)

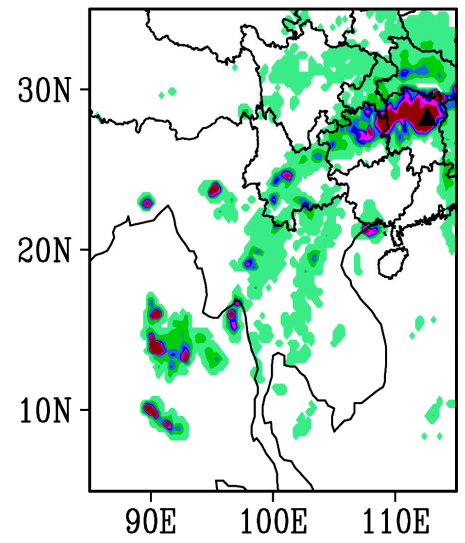

(b)

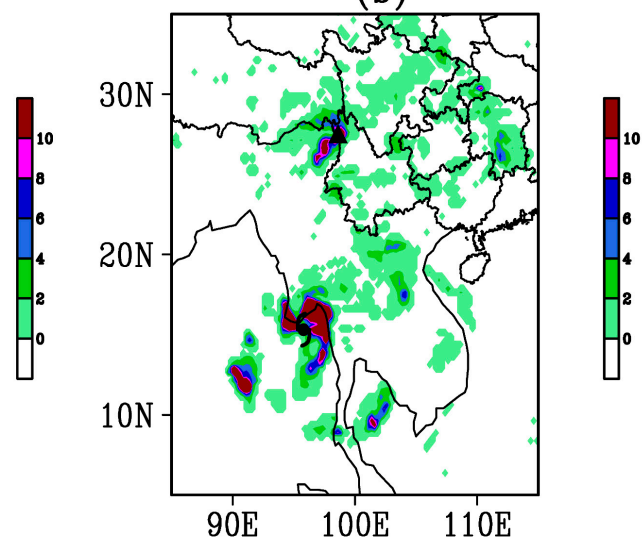

(d)

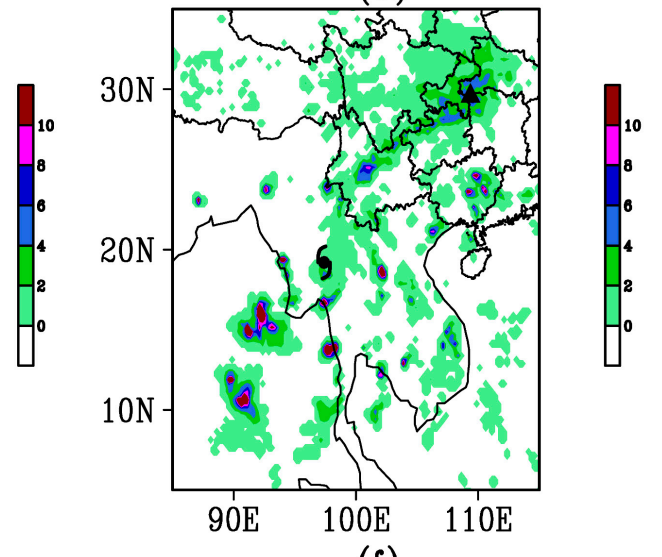

(f)

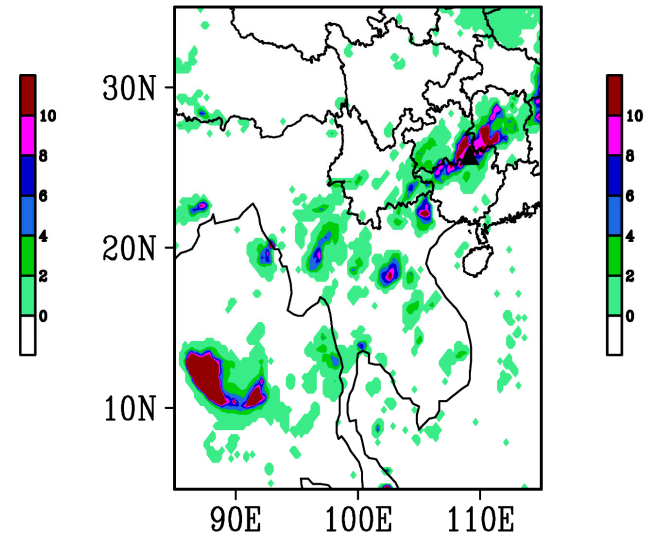

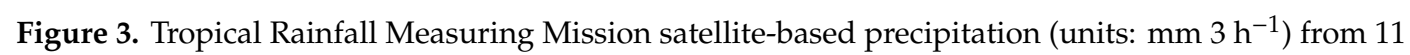
to 13 May 2002. (a) 00:00 on 11 May 2002, (b) 21:00 on 11 May 2002, (c) 00:00 on 12 May 2002, (d) 12:00 on 12 May 2002, (e) 21:00 on 12 May 2002, and (f) 15:00 on 13 May 2002. The locations of the tropical cyclone are indicated by black tropical storm symbols. The centers of maximum precipitation are indicated by black triangles. 


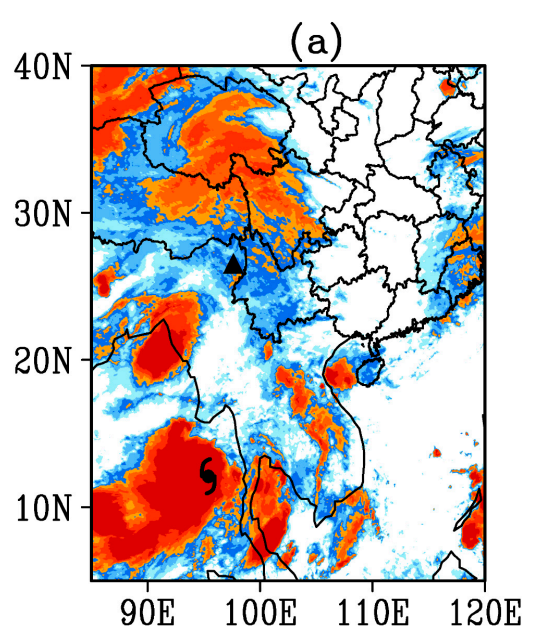

(c)

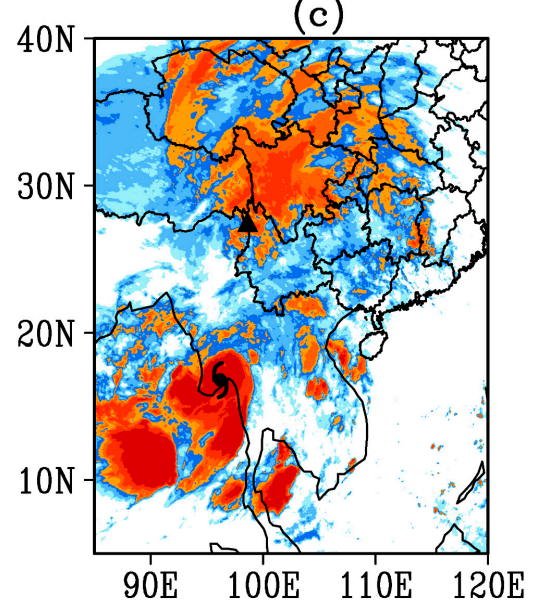

(e)

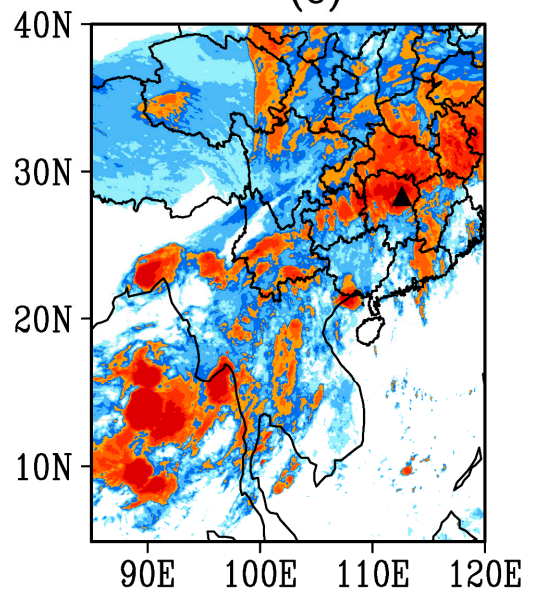

(b)

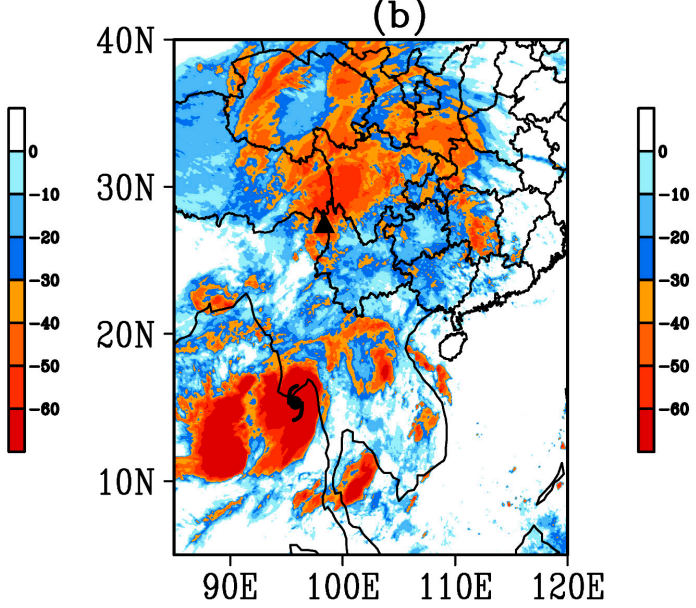

(d)

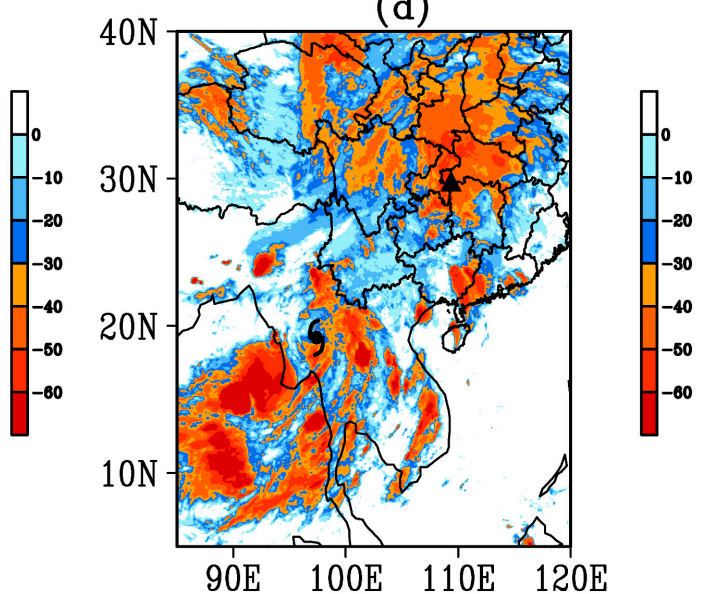

(f)

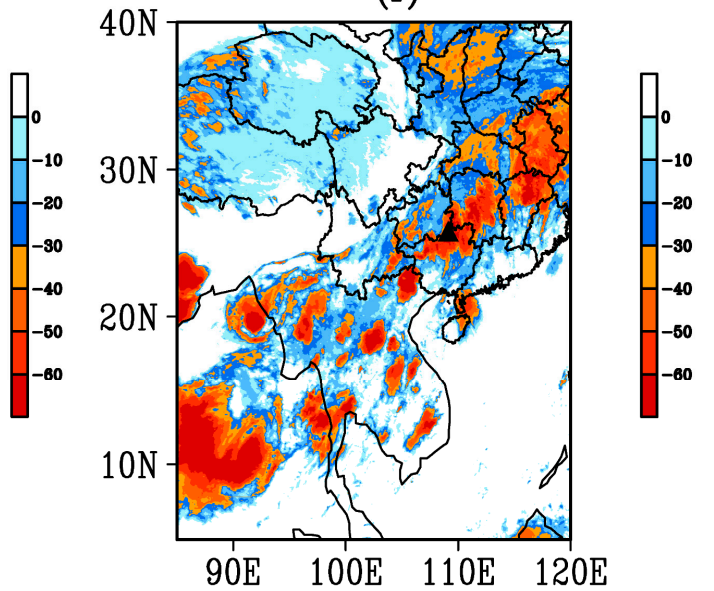

Figure 4. Black body temperature (units: ${ }^{\circ} \mathrm{C}$ ) from 11 to 13 May 2002. (a) 00:00 on 11 May 2002, (b) 21:00 on 11 May 2002, (c) 00:00 on 12 May 2002, (d) 12:00 on 12 May 2002, (e) 21:00 on 12 May 2002, and (f) 15:00 on 13 May 2002. The locations of the tropical cyclone are indicated by black tropical storm symbols. The centers of maximum precipitation are indicated by black triangles.

The TC was dissipated at 12:00 on 12 May (Figure 4d) and the rainfall near the TC weakened and gradually disappeared (Figure 3d). It should be noted that the BOB TC was separated by a certain long distance from China. The TC weakened rapidly when approaching southwestern China as a result of friction from the land and the blocking effect of the high mountains. However, the satellite cloud images suggest that the remnant of the BOB TC remained active for a few days after TC's dissipation. 
As the remnant of the TC moved downstream to the east (Figure $4 \mathrm{~d}-\mathrm{f}$ ), a zonal belt of heavy rainfall extended from southwestern China to the middle to lower reaches of the Yangtze-Huaihe river basin (Figure $3 \mathrm{~d}-\mathrm{f}$ ). This remnant was active for a few days after dissipation of the TC and generated strong rainfall in southern China until 14 May.

The 3-h TRMM rainfall analyses suggest that the continuous rainfall event in southern China from 11 to 13 May associated with the TC in the BOB can be considered as two different processes. The first heavy rainfall process from 00:00 on 11 May to 00:00 on 12 May can be considered as a PRE occurring far ahead of the TC but may have been initially associated with the advection of moisture near to the TC vicinity. The second heavy rainfall process from 12:00 on 12 May to 00:00 on 14 May resembled a rainfall event from a remnant of a tropical cyclone. Both the TRMM and CMA observational datasets showed that similar consecutive heavy rainfall processes occurred in southern China from 11 to 13 May associated with TC activity in the BOB (Figure 5). Heavy rainfall mainly occurred over the southeastern Qinghai-Tibetan Plateau on 11 May, far ahead of the TC in the BOB (Figure 5a,b), suggesting that the heavy rainfall event over southwestern China on 11 May may be treated as a PRE. The TC was already dissipated on 13 May, but a zonal belt of heavy rainfall extended from southwestern China to the middle to lower reaches of the Yangtze-Huaihe river basin (Figure 5e,f). This seems like a heavy rainfall process related to the TC remnant. Heavy rainfall belt expands from southwestern to southeastern China on 12 May, suggesting a mixture of predecessor and remnant rainfall events associated with the TC. 
(a)

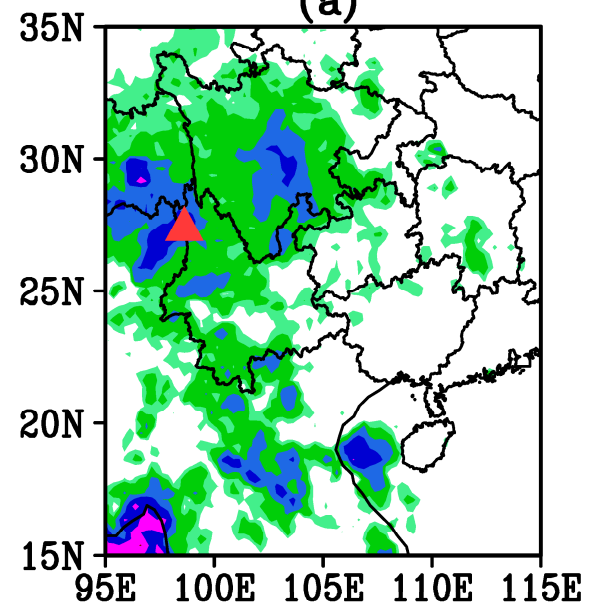

(c)

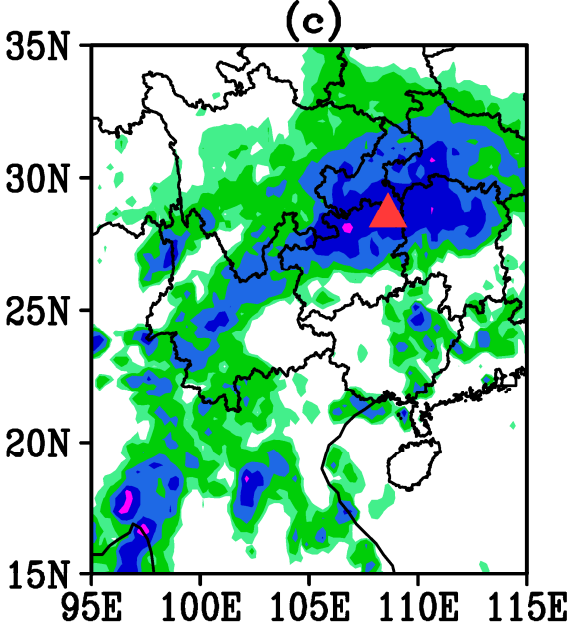

(e)

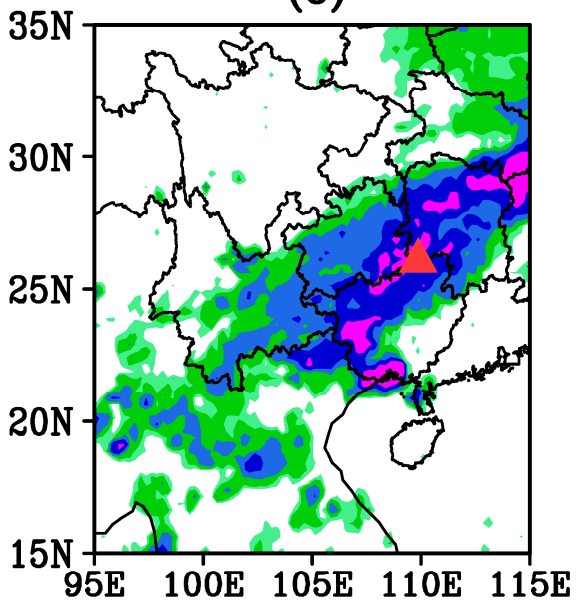

(b)

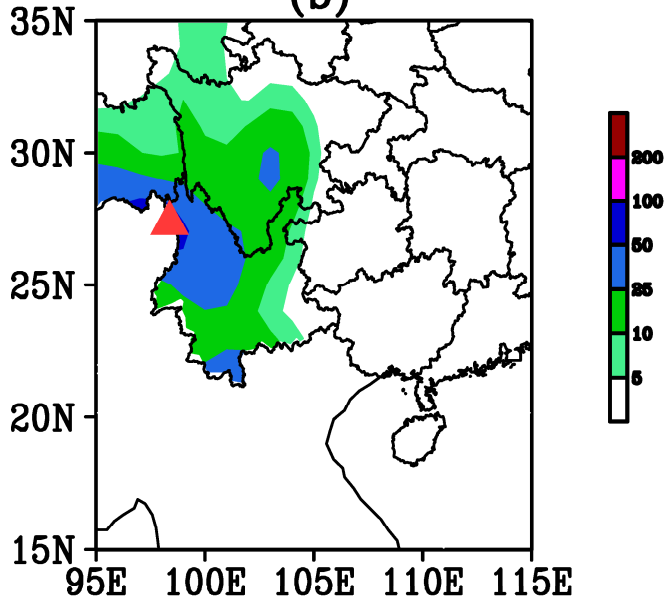

(d)

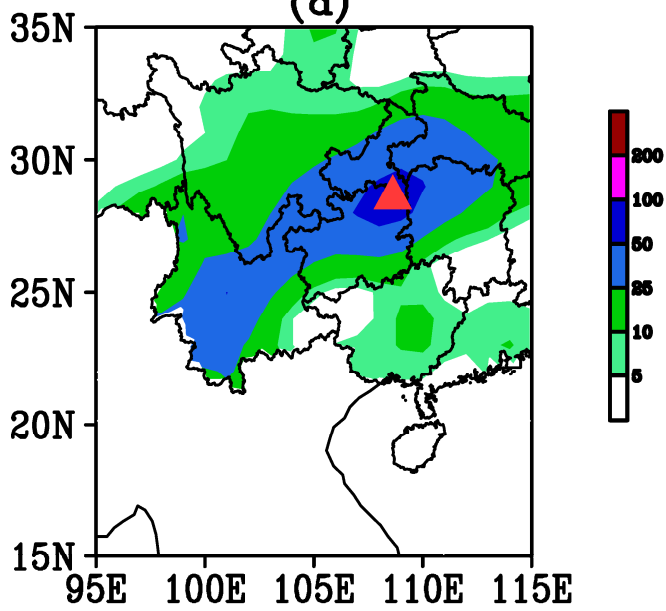

(f)

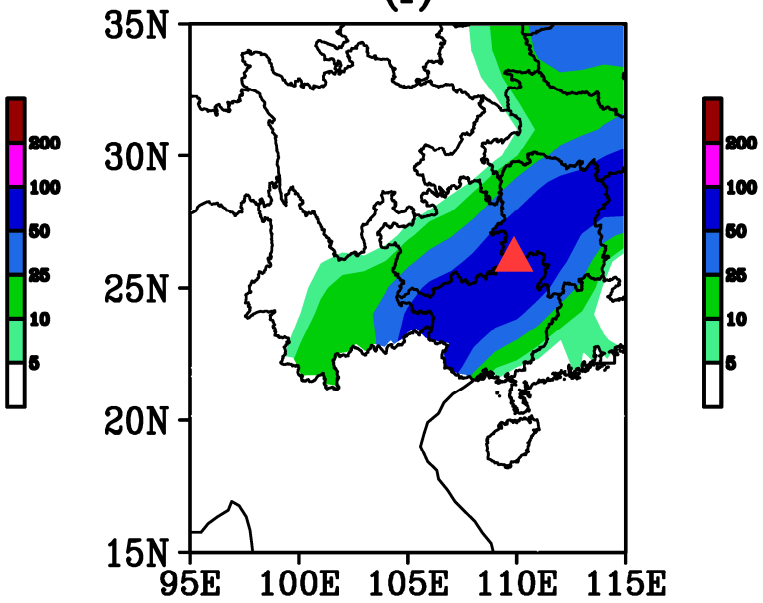

Figure 5. Daily precipitation (units: $\mathrm{mm} \mathrm{day}^{-1}$ ) on (a,b) 11 May 2002, (c,d) 12 May 2002 and (e,f) 13 May 2002. The left (right) panels are for the Tropical Rainfall Measuring Mission (China Meteorological Administration) datasets. The centers of maximum precipitation are indicated by triangle symbols.

\subsection{Air Parcel Transport Trajectories Associated with the Heavy Rainfall Event}

To verify whether the heavy rainfall events in southern China were related to the TC in BOB, we utilized the HYSPLIT model to calculate the forward (backward) air parcel transport trajectories in the vicinity of TCs (heavy rainfall regions) in the BOB (southern China). We ran three sets of the air parcel transport trajectory calculations. 
First, the forward air parcel transport trajectories around the TC genesis region in $\mathrm{BOB}\left(5-15^{\circ} \mathrm{N}\right.$, 90-100 ${ }^{\circ}$ E) were calculated as follows: Air parcels were released from the locations of each 1 by $1^{\circ}$ grid area. The air parcels were released at the time of 06:00 on 9 May, the time of TC genesis. The forward tracking began at $3000 \mathrm{~m}$ height above the surface. The calculated $120 \mathrm{~h}$ forward air parcel transport trajectories are shown in Figure 6a. Most of the forward air parcel trajectories were transported from the TC vicinity in BOB to southwestern China on 11-12 May, and in consequence, moved further eastward downstream to the middle to lower reaches of the Yangtze-Huaihe river basin on 13-14 May (Figure 6a). This indicates that the air parcels and associated moisture in the BOB TC vicinity can be transported to and influence the whole of southern China.

Second, the backward air parcel transport trajectories over the heavy rainfall region in southwestern China $\left(23-29^{\circ} \mathrm{N}, 96-103^{\circ} \mathrm{E}\right)$ were calculated on each 1 by $1^{\circ}$ grid area. The backward tracking began at $1500 \mathrm{~m}$ height above the surface and at the time of the heavy rainfall occurred over southwestern China at 12:00 on 11 May. The calculated $72 \mathrm{~h}$ backward air parcel transport trajectories are shown in Figure $6 \mathrm{~b}$. The result shows that approximately $50 \%$ of the air parcel trajectories ( 24 in a total of 49 ) that released from the heavy rainfall region in southwestern China originated from the BOB TC vicinity. This confirms that heavy rainfall event occurred in southwestern China on 11 May was closely related to the TC in $\mathrm{BOB}$ and can be treated as a PRE. In addition, there were also many of the trajectories around the base of the India-Burma trough.

Third, the backward air parcel transport trajectories over the heavy rainfall region in the middle to lower reaches of the Yangtze-Huaihe river basin $\left(25-30^{\circ} \mathrm{N}, 105-115^{\circ} \mathrm{E}\right)$ were calculated on each 1 by $1^{\circ}$ grid area. The backward tracking was beginning at $3000 \mathrm{~m}$ height above the surface and at the time of the heavy rainfall occurred over the middle to lower reaches of the Yangtze-Huaihe river basin at 12:00 on 13 May. The calculated $96 \mathrm{~h}$ backward air parcel trajectories are shown in Figure 6c. The result shows that the air particles in the heavy rainfall region of the middle to lower reaches of the Yangtze-Huaihe river basin mainly originated from near the TC in the BOB, and this case can be treated as a BOB TC remnant event.

Hence, the results of the HSPLIT model calculation confirm that heavy rainfall processes in southern China, including both the PRE in the southwestern China and TC remnant event in the middle to lower reaches of the Yangtze-Huaihe river basin, are closely associated with TC activity in the BOB.

(a) Forward trajectories starting at 0600 UTC 09 May 02

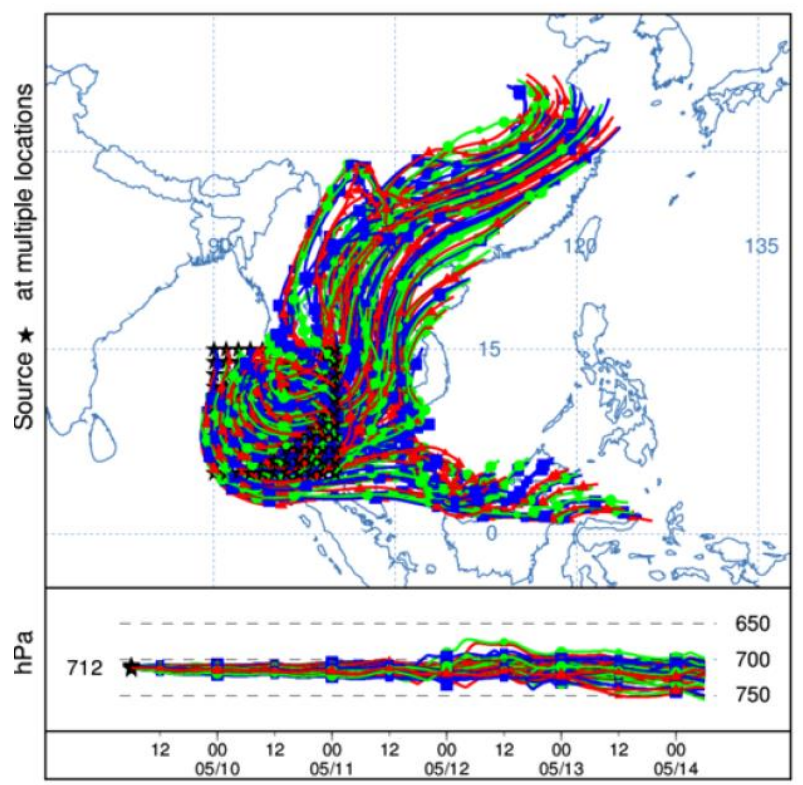

Figure 6. Cont. 
(b) Backward trajectories ending at 1200 UTC 11 May 02

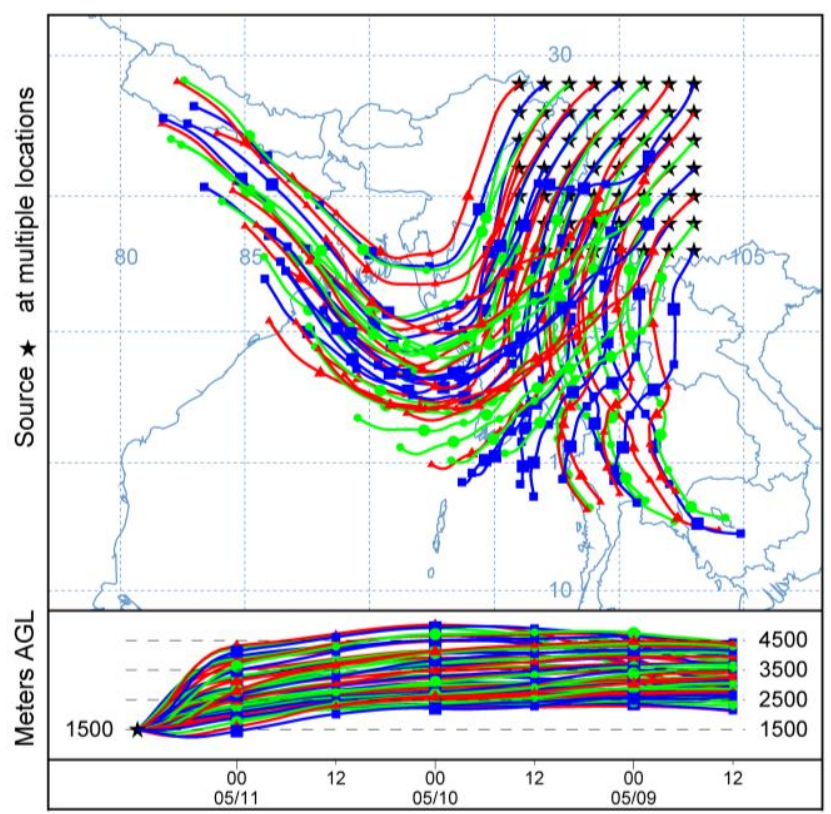

(c) Backward trajectories ending at 1200 UTC 13 May 02

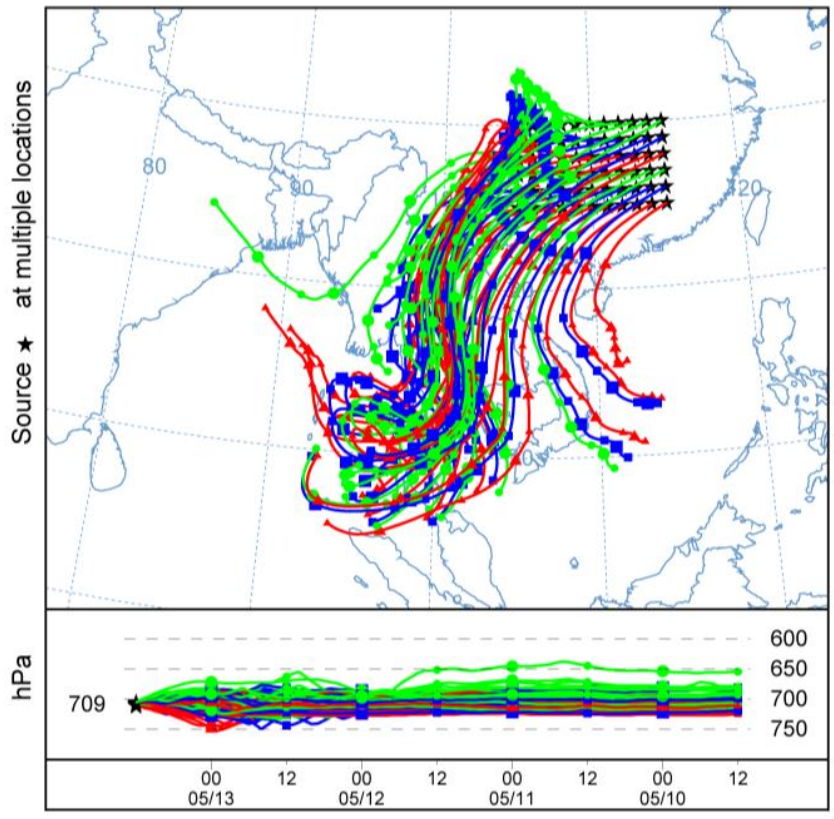

Figure 6. Air particle transport trajectories calculated by the HISPLIT model. (a) 120-h forward tracing trajectories originating from near the tropical cyclone $\left(5-15^{\circ} \mathrm{N}, 90-100^{\circ} \mathrm{E}\right)$ in the Bay of Bengal starting at 06:00 on 9 May 2002 and $3000 \mathrm{~m}$ height above the surface. (b) 72-h backward tracing trajectories originating from the region of heavy rainfall in southwestern China $\left(23-29^{\circ} \mathrm{N}, 96-103^{\circ} \mathrm{E}\right)$ starting at 12:00 on 11 May 2002 and $1500 \mathrm{~m}$ height above the surface. (c) 96-h backward tracing trajectories originating from the region of heavy rainfall in the middle to lower reaches of the Yangtze-Huaihe river basin $\left(25-30^{\circ} \mathrm{N}, 105-115^{\circ} \mathrm{E}\right)$ starting at 12:00 on 13 May 2002 and $3000 \mathrm{~m}$ height above the surface. The air parcels were released from locations of each 1 by $1^{\circ}$ grid area. 


\subsection{Synoptic-Scale Circulation Environments}

The TC was located in the northeastern BOB on 11 May and the India-Burma trough was in the south of the Qinghai-Tibetan Plateau, with the base of the trough stretching into the northern BOB (Figure 7a). An anomalous meridional negative geopotential height occurred from the southeastern BOB to the southeastern Qinghai-Tibetan Plateau, reflecting the signals of both the TC and the India-Burma trough. The western Pacific subtropical high expanded to the South China Sea and the eastern Indo-Chinese Peninsula. An abnormal positive geopotential height ridge appeared at $500 \mathrm{hPa}$ in the region $\left(25-40^{\circ} \mathrm{N}, 110-120^{\circ} \mathrm{E}\right)$. The atmospheric circulation in the mid-troposphere presented as a belt (barrier) of anomalous meridional negative (positive) geopotential height west (east) of $110^{\circ} \mathrm{E}$ in the subtropical and mid-latitude regions (Figure 7a). A strong zonal gradient of pressure, therefore, appeared near $100^{\circ} \mathrm{E}$ from the Indo-Chinese Peninsula to the southeastern Qinghai-Tibetan Plateau, causing a robust westerly wind jet to blow from near the tropical cyclone in the BOB to the southeast of the Qinghai-Tibetan Plateau at $700 \mathrm{hPa}$ (Figure $7 \mathrm{~b}$ ). The low-level jet transported abundant water vapor from the $\mathrm{TC}$ vicinity in the $\mathrm{BOB}$ to southwestern China, leading to a strong convergence of water vapor (Figure 8a). The total-column precipitable water (TPW) in the southeast of the Qinghai-Tibetan Plateau was $>35 \mathrm{~mm}(>1$ SD of the climatology in May). One trough and one ridge appeared in the upper level at mid-latitudes over China. The upper level of the East Asia subtropical jet (EASJ) was ruptured, leading to strong upper-level divergence over the southeast Qinghai-Tibetan Plateau, favoring heavy rainfall (Figure 8b). 
(a)

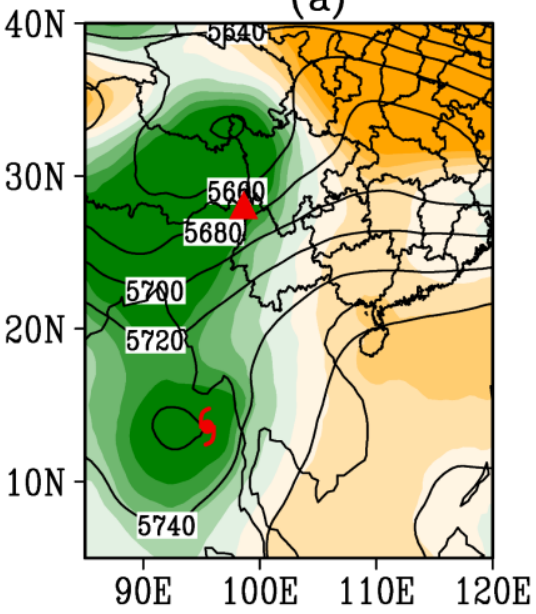

(c)

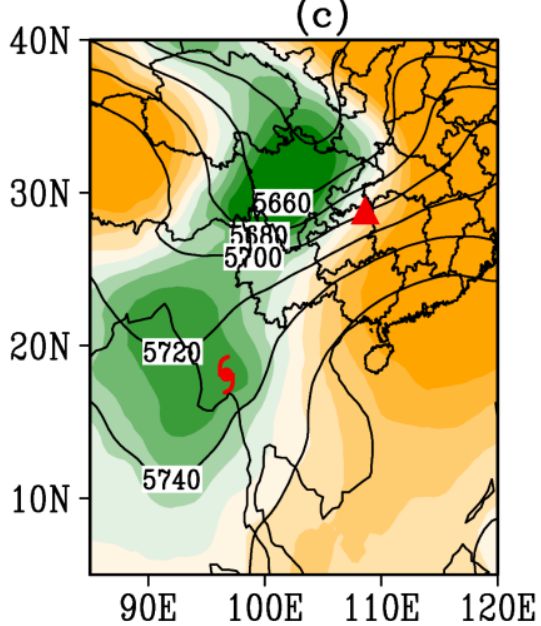

(e)

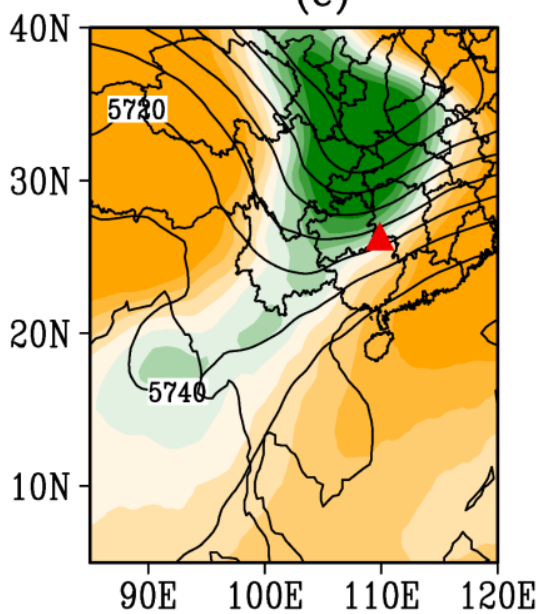

(b)

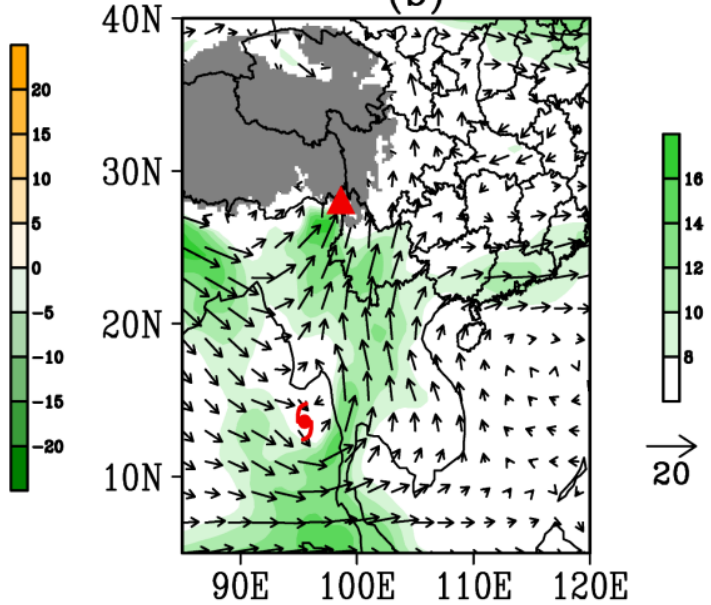

(d)
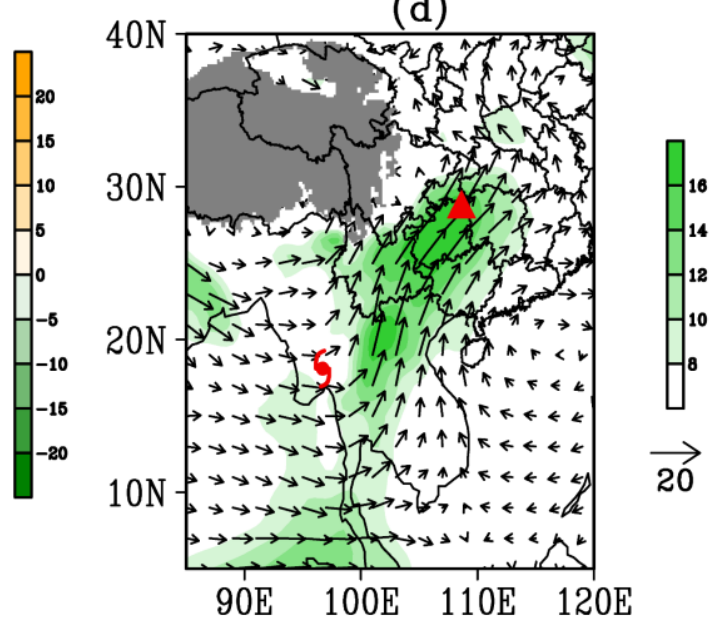

(f)

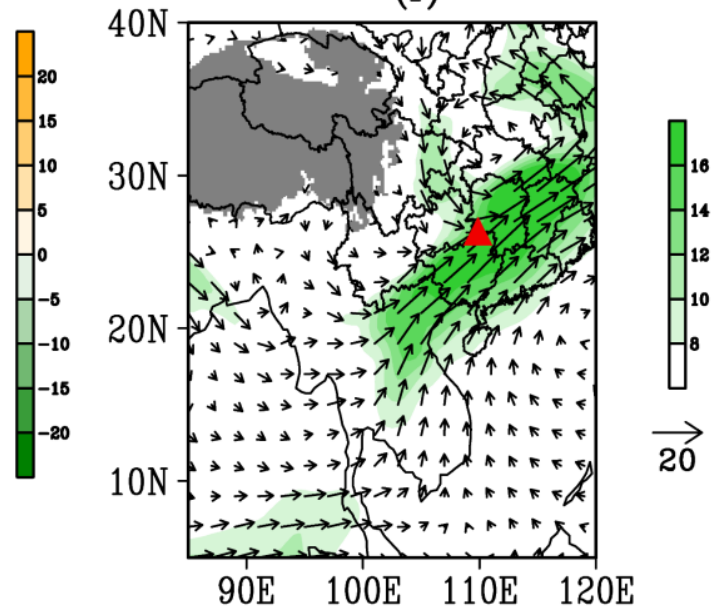

Figure 7. Geopotential height (solid lines, units: $\mathrm{m}$ ) and anomalies (shaded, units: $\mathrm{m}$ ) at $500 \mathrm{hPa}$ for (a) 11 May 2002, (c) 12 May 2002 and (e) 13 May 2002. Horizontal wind (vectors, units: $\mathrm{m} \mathrm{s}^{-1}$ ) and horizontal wind speed (shaded, units: $\mathrm{m} \mathrm{s}^{-1}$ ) at $700 \mathrm{hPa}$ for (b) 11 May 2002, (d) 12 May 2002 and (f) 13 May 2002. The locations of the tropical cyclones are indicated by black tropical storm symbols. The centers of maximum precipitation are indicated by triangle symbols. 
(a)

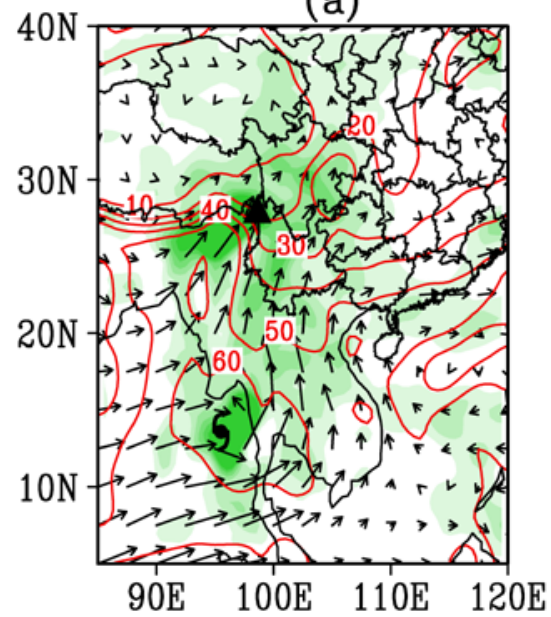

(c)

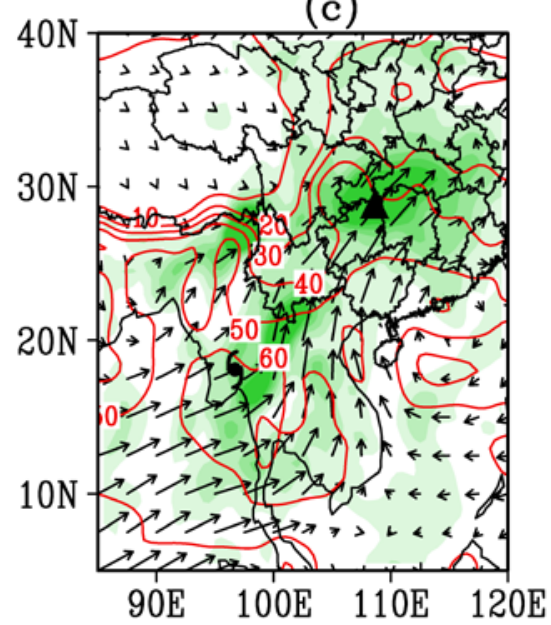

(e)

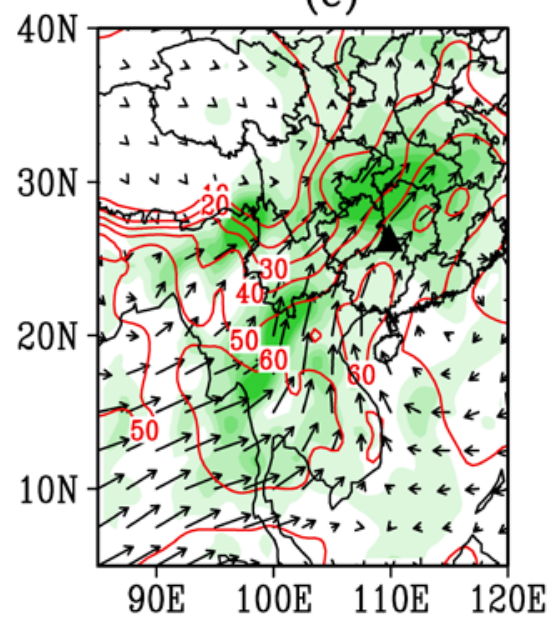

(b)

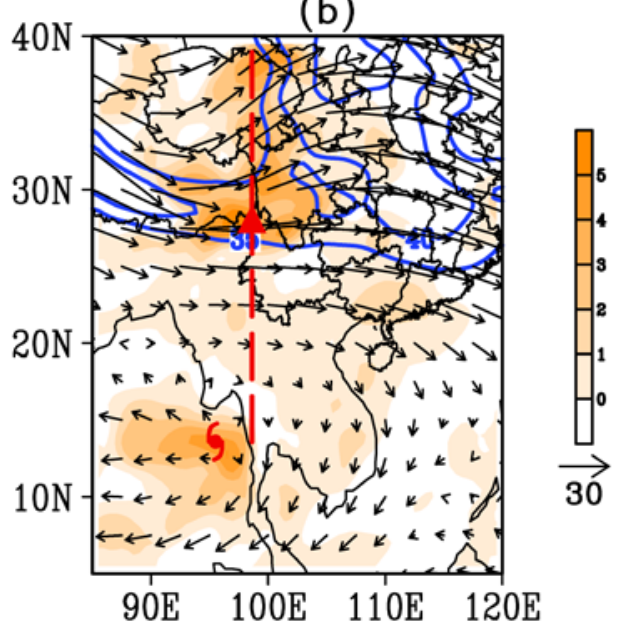

(d)

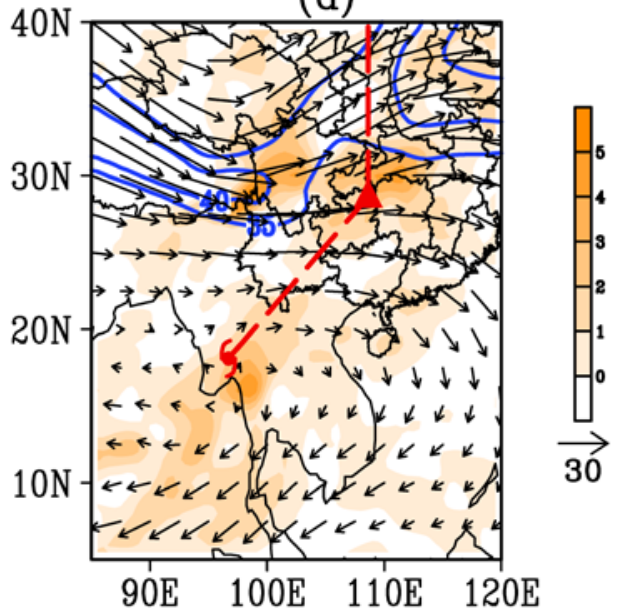

(f)

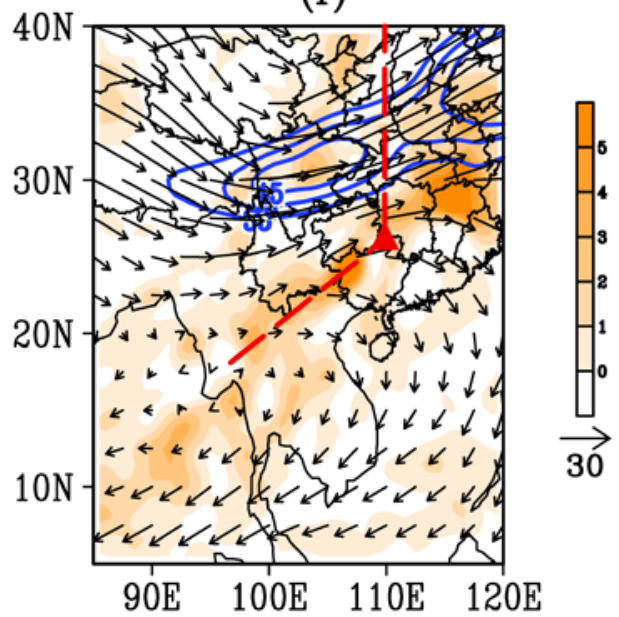

Figure 8. Column-integrated water vapor flux (vectors, units: $10^{3} \mathrm{~g} \mathrm{~m}^{-1} \mathrm{~s}^{-1}$ ), divergence of the column-integrated water vapor flux (shaded, units: $10^{-2} \mathrm{~g} \mathrm{~m}^{-2} \mathrm{~s}^{-1}$ ) and total-column precipitable water (red lines, units: mm) for (a) 11 May 2002, (c) 12 May 2002 and (e) 13 May 2002. Horizontal wind (vectors, units: $\mathrm{m} \mathrm{s}^{-1}$ ) and divergence of horizontal wind (shaded, units: $10^{-5} \mathrm{~s}^{-1}$ ) at $200 \mathrm{hPa}$ for (b) 11 May 2002, (d) 12 May 2002 and (f) 13 May 2002. The locations of the tropical cyclones are indicated by tropical storm symbols. The centers of maximum precipitation are indicated by triangle symbols. Zonal wind speeds $>35 \mathrm{~m} \mathrm{~s}^{-1}$ are indicated by purple solid lines in $(\mathbf{b}, \mathbf{d}, \mathbf{f})$. 
The TC made landfall and dissipated on 12 May, and the India-Burma trough moved eastward to southwestern China, while the subtropical high remained stable (Figure 7c). The strong gradient between the India-Burma trough and the subtropical high led to a strong southwesterly wind from west of the Indo-Chinese Peninsula to southwestern China (Figure 7d), which guided the movement of the remnant of the tropical cyclone to southwestern China (Figure 4d,e). Abundant water vapor was, therefore, transferred from the BOB and converged in southwestern China (Figure 8c). The TPW in the center of the region of heavy rainfall was $>40 \mathrm{~mm}$, providing enough water vapor for the occurrence of heavy rainfall. The upper-level EASJ moved north to $35^{\circ} \mathrm{N}$ and the region of heavy rainfall was located beneath the equatorial entrance to the upper-level subtropical jet. The upper-level divergence over the equatorial entrance to the upper-level subtropical jet also favored heavy rainfall (Figure 8d).

The TC was dissipated on 13 May, but the remnant was still active. The subtropical high was stable and expanded to the South China Sea (Figure 7e). The mid-latitude wave moved downstream to the east and an anomalous deep trough appeared over the east of the Qinghai-Tibetan Plateau. A strong southwesterly wind in front of the trough converged with the southerly flow at the periphery of the western Pacific subtropical high (Figure 7f) and contributed to guiding the TC remnant downstream to the east, conveying abundant moisture to the whole of South China (Figure 8e). Accordingly, water vapor converged in the zonal belt from southwestern China to the middle and lower reaches of the Yangtze-Huaihe river basin. The upper-level EASJ strengthened and was located near $30^{\circ} \mathrm{N}$. Strong upper-level divergence appeared south of the EASJ (Figure 8f).

\subsection{Possible Factors in the Development of Heavy Rainfall}

\subsubsection{Moisture Configuration}

As the reflection of the TC and the India-Burma trough, a meridional belt of abnormally low geopotential height expanded from the BOB to the southeast of the Qinghai-Tibetan Plateau on 11 May (Figure 7a). The abnormally low pressure in the BOB and the high pressure of the subtropical high in the South China Sea strengthened the pressure gradient, leading to a strong southerly flow on the eastern coast of the BOB and southeast of the Qinghai-Tibetan Plateau (Figure 7b). This southerly flow steered the TC and conveyed abundant water vapor from near the TC to the Qinghai-Tibetan Plateau (Figure 8a). In Figure 8b, the red line shows the route from near the TC to the center of the region of heavy rainfall in the southeast of the Qinghai-Tibetan Plateau, and Figure 9a shows a detailed vertical cross-section of the moisture configuration. The moisture originating from near the TC vicinity is conveyed poleward to the southeast of the Qinghai-Tibetan Plateau. Moisture clearly ascends along the windward side as a result of orographic lifting and an anomaly in the relative humidity appears from the ground to $300 \mathrm{hPa}$ with a center at about $600 \mathrm{hPa}$ (Figure 9a). The abundant moisture originating from near the TC deepened the moist layer throughout the troposphere and favored heavy rainfall to the southeast of the Qinghai-Tibetan Plateau, far ahead of the TC. 


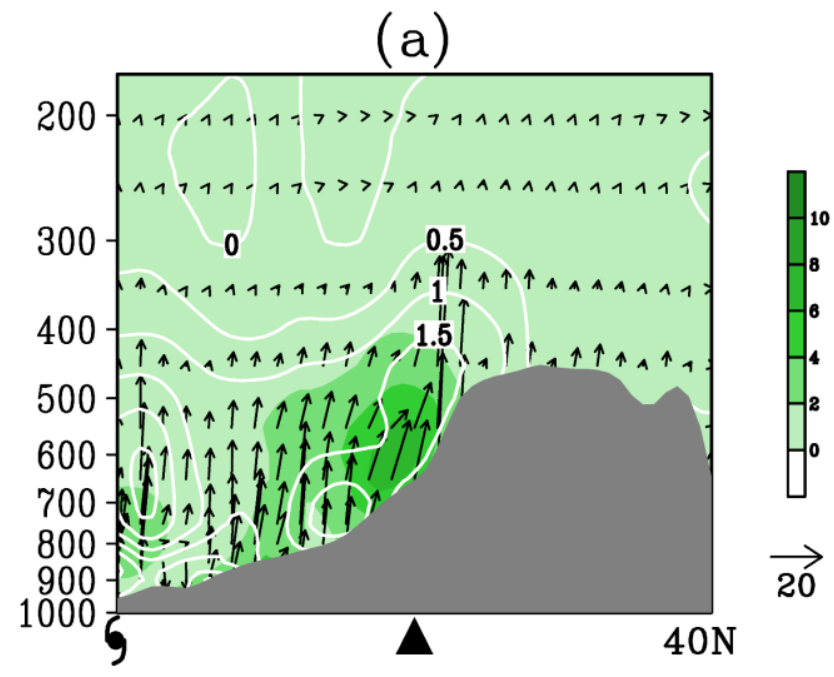

(b)

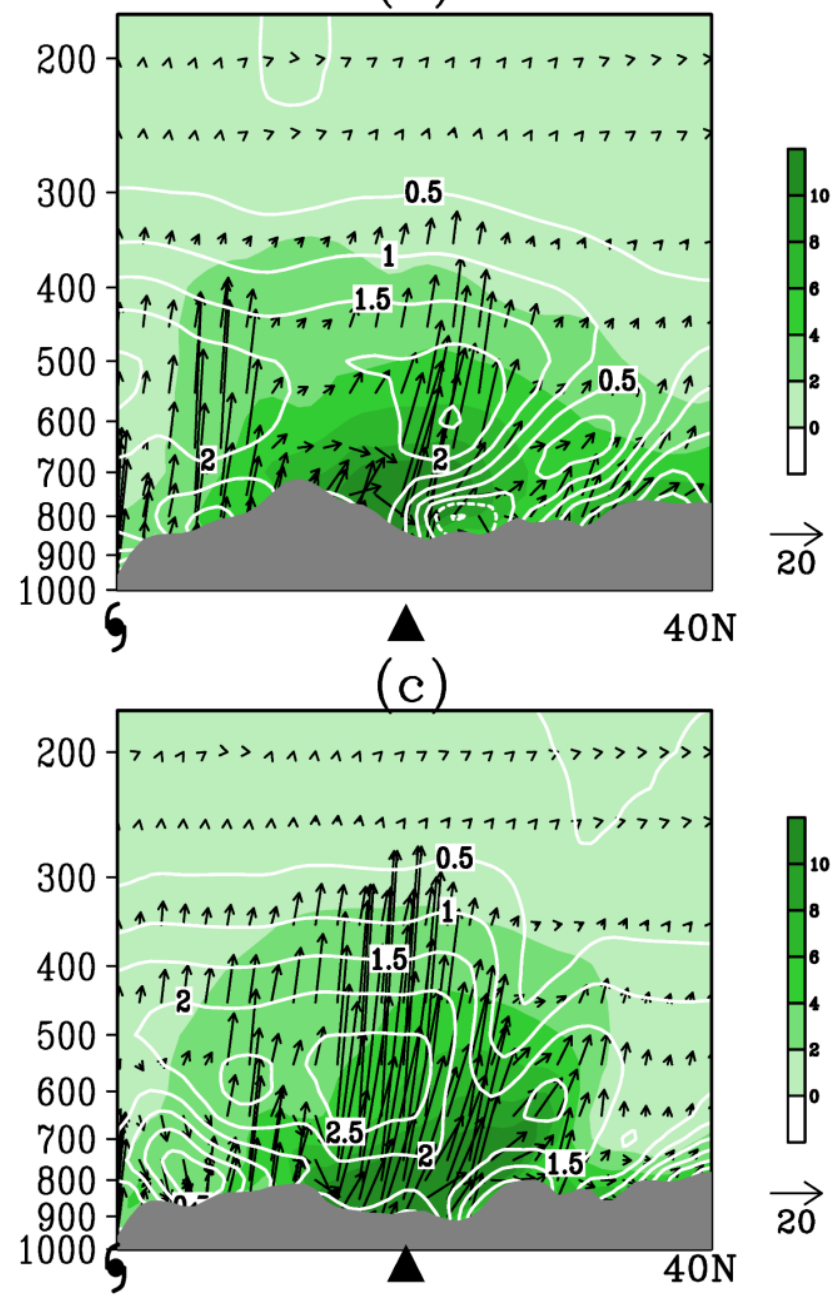

Figure 9. Vertical cross-sections of water vapor flux (horizontal direction vector, units: $10^{-2} \mathrm{~m} \mathrm{~s}^{-1}$, vertical direction units: $10^{-5} \mathrm{~m} \mathrm{~s}^{-1}$ ), magnitude of water vapor flux (shaded, unit: $10^{-2} \mathrm{~m} \mathrm{~s}^{-1}$ ), and anomalous specific humidity (contour, unit: $\mathrm{g} \mathrm{kg}^{-1}$ ) along the red dotted line segments shown in Figure 8b,e and f on (a) 11 May 2002, (b) 12 May 2002, and (c) 13 May 2002, respectively. The locations of the tropical cyclones are indicated by black tropical storm symbols. The centers of maximum precipitation are indicated by triangle symbols. 
As the TC approached and made landfall on the west coast of the Indo-China Peninsula on 12 May, a robust southwesterly low-level jet expanded from near the TC to southwestern China (Figure 7d). This low-level jet provided a favorable corridor to convey moisture from the BOB to southwestern China. The TPW in the center of the region of heavy rainfall in southwestern China was $>40 \mathrm{~mm}$ (Figure 8c). A deep horizontal southwesterly flux of water vapor along the vertical cross-section between the TC and the region of heavy rainfall in southwestern China was seen from the ground to $400 \mathrm{hPa}$ on 12 May. Associated with the strong upward transport of moisture, a region of abnormal relative humidity extended from the lower to the upper level over the region of heavy rainfall in southwestern China, with an anomalous center located at $600 \mathrm{hPa}$ (Figure 9b).

Although the TC was dissipated on May 13, the remnant was steered downstream to the east (Figure 7f) as a result of the strong southwesterly low-level jet caused by the strong pressure gradient between the mid-latitude trough at $110^{\circ} \mathrm{E}$ and the subtropical high in the South China Sea (Figure 7e). A broad plume of moist air characterized by high TPW values extended from the western BOB to southern China (Figure 8e). The robust upward transport of moisture extended to $300 \mathrm{hPa}$ from the location of dissipation of the tropical cyclone to the center of heavy rainfall in southern China. Thus, the moisture layer was deepened throughout almost all the troposphere, with the maximum anomalies in relative humidity at lower to mid-levels (Figure 9c). The vertical structure of the moisture configuration led to thickening of the saturated moisture layer and favored heavy rainfall over southern China.

\subsubsection{Physical Lifting and Frontogenesis}

On 11 May, the southerly wind flow originating from the eastern flank of the TC in the BOB conveyed warm, moist air northeast to the southeast of the Qinghai-Tibetan Plateau (Figure 10a). The topography in the south of the Qinghai-Tibetan Plateau is higher in the northwest and lower in the southeast. A southerly flow, therefore, causes the convergence of warm, moist air and forces strong upward motion on the windward slope of the mountains located in the southeast of the Qinghai-Tibetan Plateau. The convergence of warm air in the southeast of the Qinghai-Tibetan Plateau leads to strong frontogenesis (Figure 10b). Strong warm air advection originating from near the TC and upward motion occurred from the ground to the top of the troposphere over the region of heavy rainfall in the southeast of the Qinghai-Tibetan Plateau (Figures 11a and 10b). 
(a)

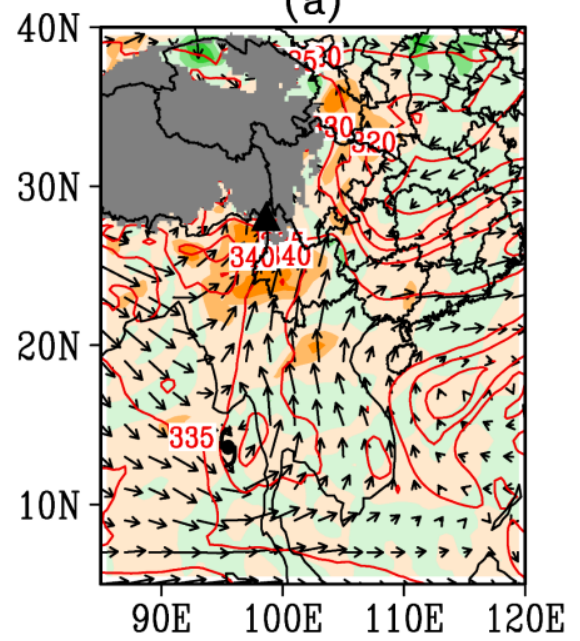

(c)

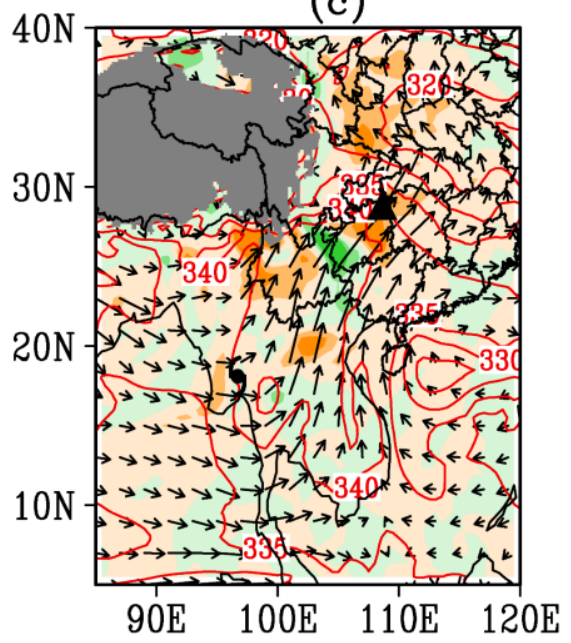

(e)

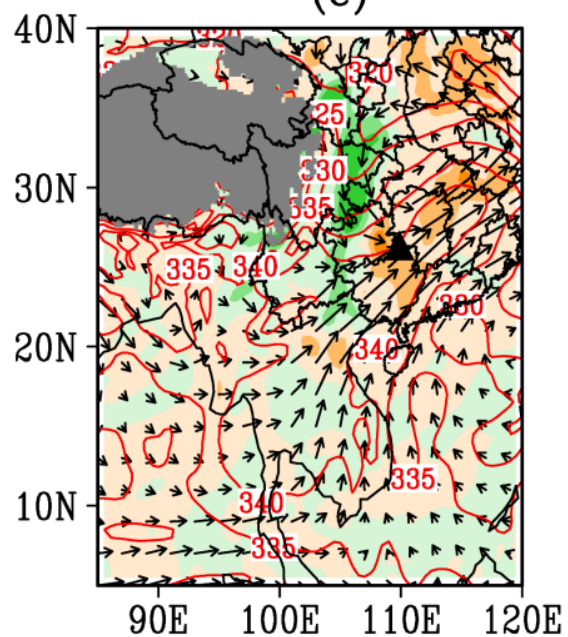

(b)

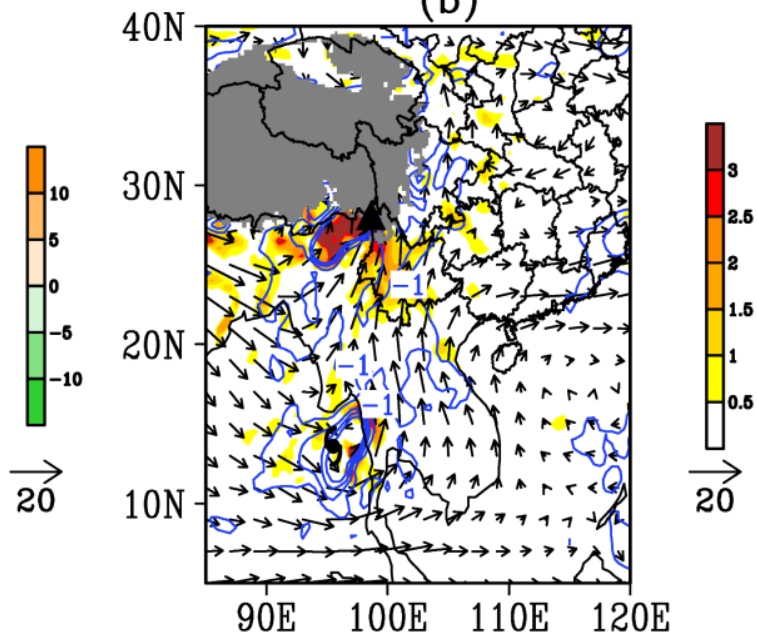

(d)

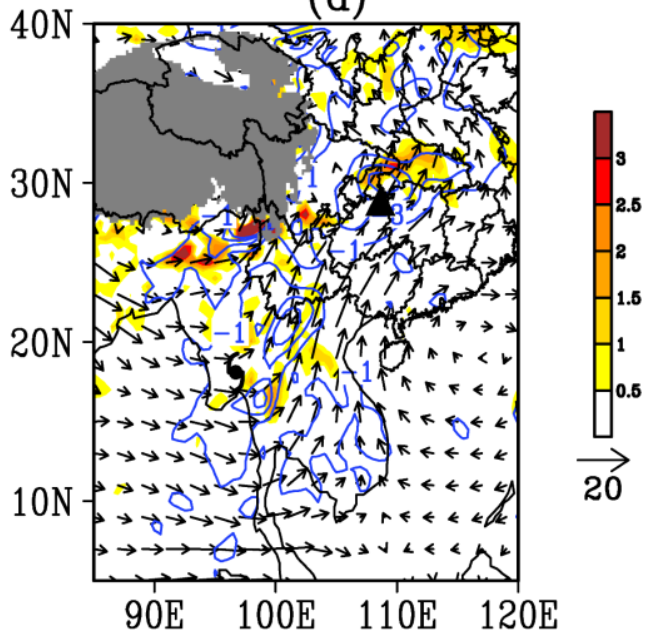

(f)

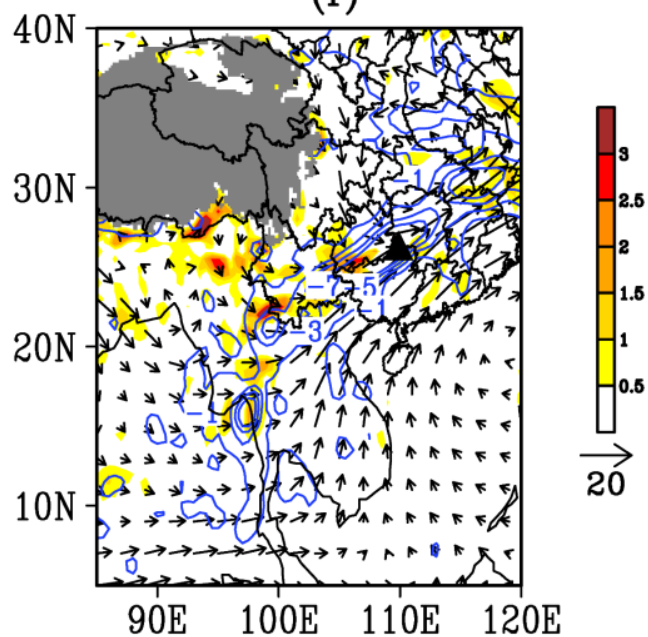

Figure 10. Horizontal wind (vector, units: $\mathrm{m} \mathrm{s}^{-1}$ ), horizontal temperature advection (shaded, units: $10^{-5} \mathrm{~K} \mathrm{~s}^{-1}$ ), and equivalent potential temperature (red contour, units: $\mathrm{K}$ ) at $700 \mathrm{hPa}$ for (a) 11 May 2002, (c) 12 May 2002, (e) 13 May 2002. And frontogenesis (shaded, units: $10^{-9} \mathrm{~K} \mathrm{~m}^{-1} \mathrm{~s}^{-1}$ ) at $700 \mathrm{hPa}$ and vertical pressure velocity (the values less than 0 are indicated in blue contours, units: $10^{-2}$ pa s$^{-1}$ ) at $500 \mathrm{hPa}$ for (b) 11 May 2002, (d) 12 May 2002, (f) 13 May 2002. The locations of the tropical cyclones are indicated by black tropical storm symbols. The centers of maximum precipitation are indicated by triangle symbols. 

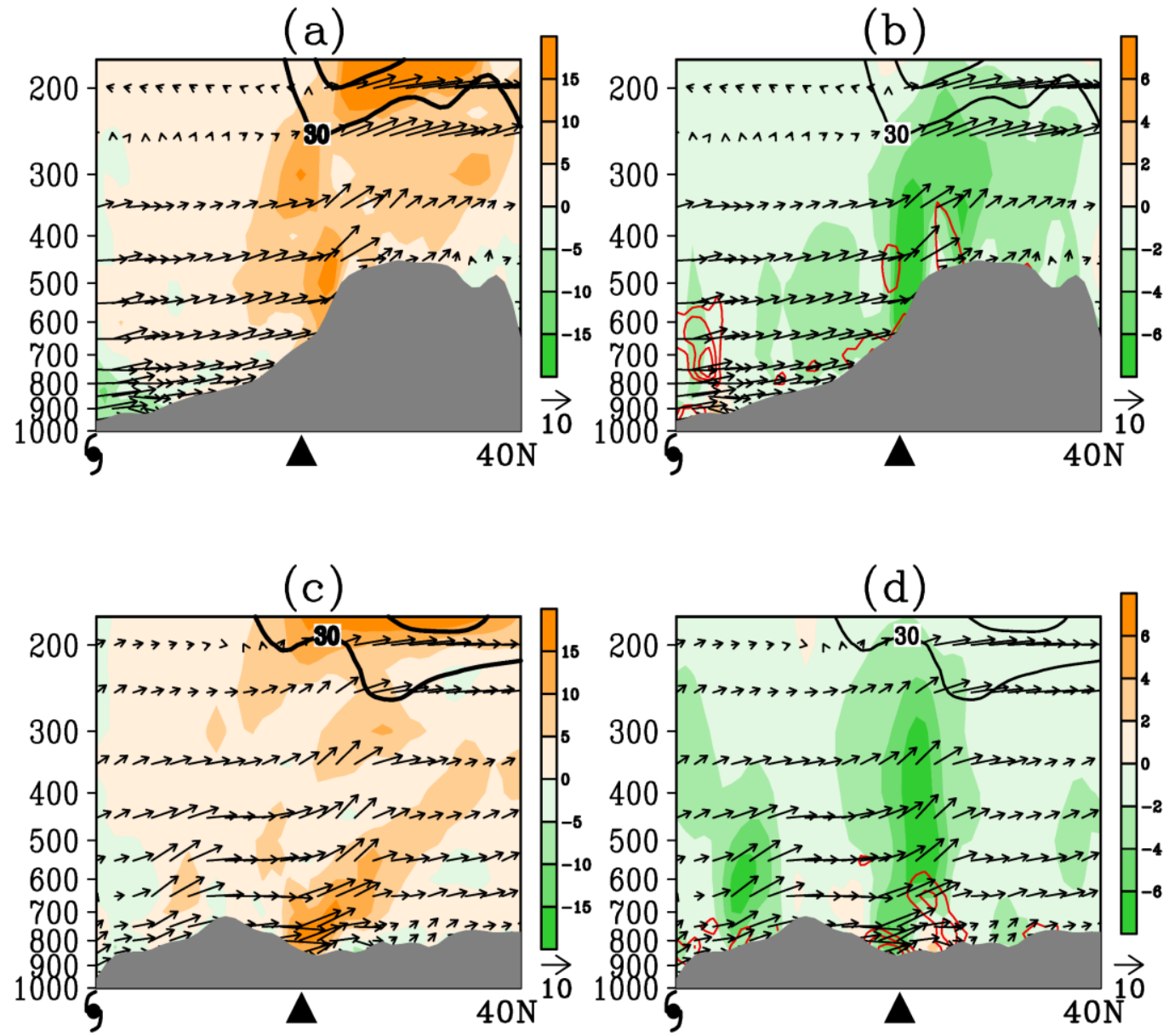

(e)

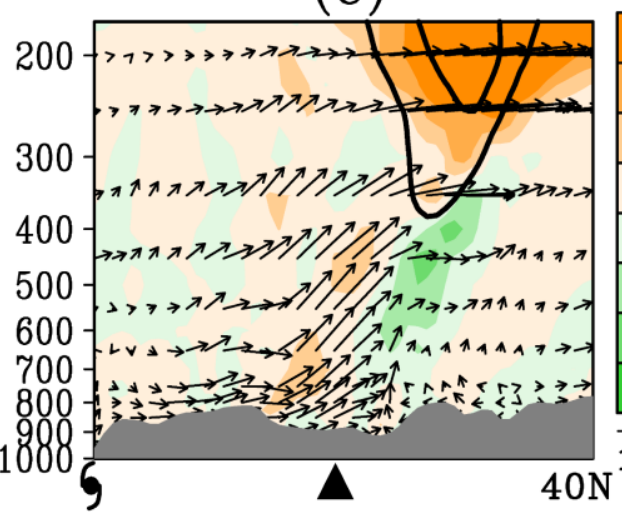

(f)

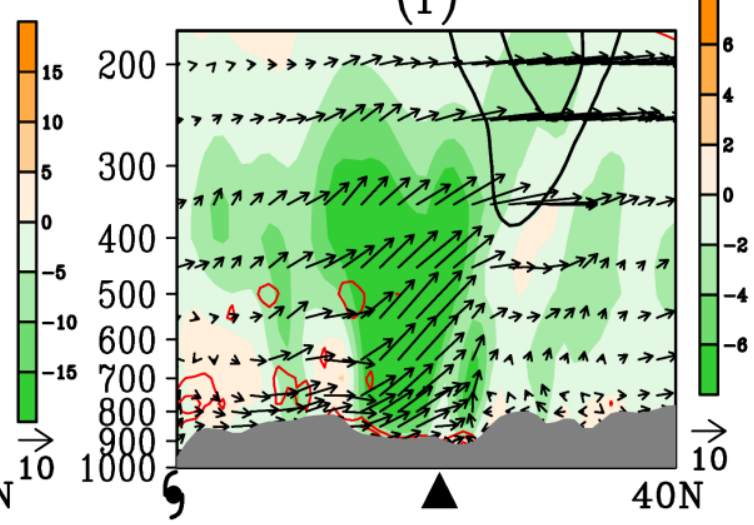

Figure 11. The same as Figure 9, but for horizontal temperature advection (shaded, units: $10^{-5} \mathrm{~K} \mathrm{~s}^{-1}$ ), wind flow anomaly (vector, the horizontal flow in $\mathrm{m} \mathrm{s}^{-1}$, and the vertical flow is in $10^{-2} \mathrm{pa} \mathrm{s}^{-1}$ ) and zonal wind speed (every $5 \mathrm{~m} \mathrm{~s}^{-1}$ from $35 \mathrm{~m} \mathrm{~s}^{-1}$, black lines) on (a) 11 May 2002, (c) 12 May 2002 and (e) 13 May 2002. And frontogenesis (red lines, every $1 \times 10^{-9} \mathrm{~K} \mathrm{~m}^{-1} \mathrm{~s}^{-1}$ from $1 \times 10^{-9} \mathrm{~K} \mathrm{~m}^{-1} \mathrm{~s}^{-1}$ ), vertical pressure velocity (shaded, units: $10^{-2}$ pa s$^{-1}$ ), wind flow anomaly (vector, the horizontal flow in $\mathrm{m} \mathrm{s}^{-1}$, and the vertical flow is in $10^{-2} \mathrm{pa} \mathrm{s}^{-1}$ ) and zonal wind speed (every $5 \mathrm{~m} \mathrm{~s}^{-1}$ from $35 \mathrm{~m} \mathrm{~s}^{-1}$, black lines) on (b) 11 May 2002, (d) 12 May 2002 and (f) 13 May 2002. 
Associated with the approach and landfall of the TC on 12 May, a strong, low-level southwesterly jet conveying warm, moist air converged in southwestern China, where there was an equivalent potential temperature ridge at $700 \mathrm{hPa}$ (Figure 10c). Deep southwesterly warm advection originating from near the TC was conveyed to the region of heavy rainfall over southwestern China from the base to the top of the troposphere (Figure 11c). A cold wind flow intruded southward along the eastern edge of the Qinghai-Tibetan Plateau and encountered the southerly warm, moist air originating from the near the TC in the BOB, forcing upward motion and leading to frontogenesis in southwestern China (Figures 10d and 11d).

On 13 May, the TC remnant was steered downstream to the east to southern China by the low-level southwesterly jet and warm, moist air was advected to southern China. The advection of warm air was weakened as a result of the dissipation of the TC (Figures 10e and 11e). However, the intrusion of cold air from the eastern edge of the Qinghai-Tibetan Plateau strengthened (Figures 10e and 11e). The strong cold flow was therefore juxtaposed with the warm, moist advection caused by the remnant of the TC, leading to strong frontogenesis in southern China (Figure 10f).

\subsubsection{Role of the Upper-Level EASJ}

The heavy rainfall events matured beneath the equatorward entrance of the upper-level EASJ from 11 to 13 May (Figure 8b,d,f). This suggests that the upper-level EASJ may play an important part in the heavy rainfall processes. The EASJ was ruptured near $100^{\circ} \mathrm{E}$ on May 11 and the strong divergence of the equatorward entrance of the EASJ favored upward lifting and heavy rainfall (Figure 11b). The EASJ moved downstream to the east on 12 May (Figure $8 \mathrm{~d}$ ). The region of heavy rainfall also moved eastward to southwestern China. The EASJ was steady on 13 May but strengthened (Figure $8 \mathrm{f}$ ) and the mid- to upper-level upward motion in the equatorward entrance region of the EASJ also became stronger. The lower to mid-level upward motion induced by the encounter of cold and warm air was coupled with the upper-level lifting caused by the sub-circulation of the EASJ, leading to consistently strong upward motion throughout the troposphere (Figures $10 \mathrm{f}$ and 11f). This is important for the upward transport of moisture, leading to instability and, therefore, favoring the occurrence of heavy rainfall even when the TC remnant was weakening.

\section{Summary and Conclusions}

As a result of the blocking effect of high mountains, tropical cyclones in the BOB do not usually influence China directly. However, they may indirectly cause heavy rainfall in China. Using a case study, we showed that a continuous heavy rainfall process in southern China was closely related to TC activity in the BOB.

Daily CMA observational and 3-h satellite-based TRMM precipitation datasets showed that continuous heavy rainfall occurred in southern China from 11 to 13 May 2002 as a result of two different processes. The first process acted as a PRE. Before the TC made landfall, it was active in the BOB and transported abundant amounts of water vapor to southwestern China, resulting in heavy rainfall. The second process was a rainfall event related to the remnant of the TC. After TC's dissipation, the remnant remained active under the favorable conditions and moved downstream to the east from southwestern China to the middle to lower reaches of the Yangtze-Huaihe river basin, where it caused heavy rainfall. Both of these heavy rainfall processes are closely related to TC activity in the BOB, although the mechanisms in the two processes are quite different.

In the PRE, the TC in the BOB acted as a source of warm, moist air. The moisture originating near the tropical cyclone was advected poleward by the low-level southerly jet. The warm, moist southerly flow was forced to ascend on the windward slope of the mountains, causing heavy rainfall in the southeast of the Qinghai-Tibetan Plateau. Orographic forcing was important in this heavy rainfall process. By contrast, in the second heavy rainfall process, the warm, moisture air carried by the TC remnant was countered by the advection of cold air from the east of the Qinghai-Tibetan Plateau, resulting in strong baroclinic frontogenesis and favoring the occurrence of heavy rainfall. Both heavy 
rainfall events occurred beneath the equatorial entrance of the upper-level EASJ. The upper-level divergence caused by the sub-circulation of the EASJ was important in both heavy rainfall processes.

In addition, the result of Yuan et al. showed that 21 cases of PREs produce heavy rainfall over southwestern China associated with tropical cyclones originating in the BOB during the period 1981-2012 [11]. Further investigation shows that 29 cases of BOB TC remnant events cause heavy rainfall in southern China. Moreover, there are 12 cases of the PRE and TC remnant events are co-occurred with the same parent TC in the BOB. During the period of 1981-2012, there were 38 of BOB TCs, approximately one BOB TC per year on average, produced heavy rainfall over southern China by causing PRE or TC remnant events among which, approximately $32 \%$ of BOB TCs (12 of total 38) caused multiple heavy rainfall processes including both the PRE and TC remnant events in southern China. This confirms that the case study in this work may reveal a common phenomenon and provide a meaningful analysis framework to better understanding the heavy rainfall processes over southern China associated with the BOB TC. And the characteristics and differences of these predecessor rain and TC remnant events are also needed to investigate from a climatological perspective in the future.

Author Contributions: Conceptualization, J.Y. (Junpeng Yuan); formal analysis, J.Y. (Junpeng Yuan); methodology, J.Y. (Junpeng Yuan); resources, J.Y. (Junpeng Yuan); writing—original draft, J.Y. (Junpeng Yuan); writing-review \& editing, J.Y. (Junpeng Yuan), T.F.; visualization, J.L., D.F., M.M., J.Y. (Juyue Yin) and L.Z.

Funding: This work was supported by the National Natural Science Foundation of China (41875109), the Natural Science Foundation of Yunnan Province (Grant No. 2018FB074), the Educational Foundation of Yunnan Province (Grant No. 2018JS014), the Yunnan Excellent Youth Fund Development Project (2018YDJQ012) and the Project of Power Construction Corporation of China (DJ-ZDZX-2016-02).

Acknowledgments: The authors thank all the scientists and crew members who were involved in the program. We also thank the reviewers for their comments, which helped to improve our paper.

Conflicts of Interest: The authors declare no conflicts of interest.

\section{References}

1. Wang, Y.Q.; Wang, Y.; Fudeyasu, H. The role of Typhoon Songda (2004) in producing distantly located heavy rainfall in Japan. Mon. Weather Rev. 2009, 137, 3699-3716. [CrossRef]

2. Chen, L.S. Study and forecast on Landfall tropical cyclone heavy rainfall. In Proceedings of the 14th Proseminar on Tropical Cyclone, Shanghai, China, 6 November 2007; pp. 3-7. (In Chinese)

3. Cote, M.R. Predecessor Rain Events in Advance of Tropical Cyclones. Master's Thesis, State University of New York, New York, NY, USA, August 2007.

4. Klein, P.M.; Harr, P.A.; Elsberry, R.L. Extratropical transition of western North Pacific tropical cyclones: Midlatitude and tropical cyclone contributions to reintensification. Mon. Weather Rev. 2002, 130, 2240-2259. [CrossRef]

5. Atallah, E.; Bosart, L.F.; Aiyyer, A.R. Precipitation distribution associated with landfalling tropical cyclones over the eastern United States. Mon. Weather Rev. 2007, 135, 2185-2206. [CrossRef]

6. Webster, P.J. Myanmar's deadly daffodil. Nat. Geosci. 2008, 1, 488-490. [CrossRef]

7. Wang, M.; Duan, X.; Li, H.H.; Liu, J.Y.; Fu, R. A sensitivity experiment to the orographic effect on the Bengal storm of Mala during its landing. Acta Meteorol. Sin. 2011, 69, 486-495. (In Chinese) [CrossRef]

8. Duan, X.; Tao, Y.; Cun, C.Q.; Guo, S.C.; Lin, Y. The spectral and temporal distributions of the Bay of Bengal storm activities. Plateau Meteorol. 2009, 28, 634-641. (In Chinese) [CrossRef]

9. Wang, Z.Q.; Zhu, W.J.; Duan, A.M. A Case Study of Snowstorm in Tibetan Plateau Induced by Bay of Bengal Storm: Based on the theory of Slantwise Vorticity Development. Plateau Meteorol. 2010, 29, 703-711. (In Chinese) [CrossRef]

10. Lü, A.M.; Wen, Y.R.; Li, Y. Study of the impact of tropical cyclone Akash (0701) over the Bay of Bengal on a heavy rainfall event in Southwest China. Chin. J. Atmos. Sci. 2013, 37, 160-170. (In Chinese) [CrossRef]

11. Yuan, J.P.; Zhao, D.; Yang, R.W.; Yang, H.F. Predecessor rain events over China's low-latitude highlands associated with Bay of Bengal tropical cyclones. Clim. Dynam. 2018, 50, 825-843. [CrossRef]

12. Xu, M.L.; Liang, H.L.; Duan, X.; Chen, X.H. Comparative analysis of precipitation difference over yunnan influenced by Bengal Bay storm in autumn. Plateau Meteorol. 2014, 33, 1229-1239. (In Chinese) 
13. Chen, L.; Li, Y.; Cheng, Z. An overview of research and forecasting on rainfall associated with landfalling tropical cyclones. Adv. Atmos. Sci. 2010, 27, 967-976. [CrossRef]

14. Moore, B.J.; Bosart, L.F.; Keyser, D.; Jurewicz, M.L. Synoptic-scale environments of predecessor rain events occurring east of the rocky mountains in association with atlantic basin tropical cyclones*. Mon. Weather Rev. 2013, 141, 1022-1047. [CrossRef]

15. Zhang, T.F.; Duan, X.; Zhang, J. Mesoscale analysis of Yunnan successive heavy precipitation caused by storms over the Bay of Bengal in the early summer. J. Trop. Meteorol. 2006, 22, 67-73. (In Chinese) [CrossRef]

16. Chu, J.H.; Sampson, C.R.; Levine, A.S.; Fukada, E. The Joint Typhoon Warning Center Tropical Cyclone Best-Tracks, 1945-2000. Available online: https://www.researchgate.net/publication/286806466_The_Joint_ Typhoon_Warning_Center_Tropical_Cyclone_Best-Tracks_1945-2000 (accessed on 9 September 2019).

17. Dee, D.P.; Uppala, S.M.; Simmons, A.J.; Berrisford, P.; Poli, P.; Kobayashi, S.; Andrae, U.; Balmaseda, M.A.; Balsamo, G.; Bauer, P.; et al. The ERA-Interim reanalysis: conFigureuration and performance of the data assimilation system. Q. J. R. Meteorol. Soc. 2011, 137, 553-597. [CrossRef]

18. Kummerow, C.; Barnes, W.; Kozu, T.; Shiue, J.; Simpson, J. The tropical rainfall measuring mission sensor package. J. Atmos. Ocean. Technol. 1998, 15, 809-817. [CrossRef]

19. Huffman, G.J.; Adler, R.F.; Curtis, S.; Bolvin, D.T.; Nelkin, E.J. Global rainfall analyses at monthly and 3-h time scales. In Measuring Precipitation From Space; Springer: Dordrecht, Holland, 2007; pp. 291-305. ISBN 978-1-4020-5835-6.

20. Kalnay, E.; Kanamitsu, M.; Kistler, R.; Collins, W.; Deaven, D.; Gandin, L.; Iredell, M.; Saha, S.; White, G.; Woollen, J.; et al. The NCEP/NCAR 40-Year Re-analysis Project. Bull. Am. Meteorol. Soc. 1996, 77, 437-472. [CrossRef]

21. Kistler, R.; Kalnay, E.; Collins, W.; Saha, S.; White, G.; Woollen, J.; Chelliah, M.; Ebisuzaki, W.; Kanamitsu, M.; Kousky, V.; et al. The NCEP-NCAR 50-Year Reanalysis: Monthly means CD-ROM and documentation. Bull. Am. Meteorol. Soc. 2001, 82, 247-267. [CrossRef]

22. Air Resources Laboratory Web Site. Available online: http://ready.arl.noaa.gov/HYSPLIT.php (accessed on 22 September 2019).

23. Ninomiya, K. Characteristics of Baiu front as a predominant subtropical front in the summer northern hemisphere. J. Meteorol. Soc. Jpn. Ser. II 1984, 62, 880-893. [CrossRef]

24. Draxler, R.P.; Hess, G.D. An overview of the HYSPLIT_4 modeling system for trajectories, dispersion, and deposition. Aust. Meteorol. Mag. 1998, 47, 295-308. 